Check for updates

Cite this: Phys. Chem. Chem. Phys., 2020, 22, 5647

Received 8th September 2019, Accepted 3rd February 2020

DOI: $10.1039 / c 9 c p 04986 j$

rsc.li/pccp

\section{Holistic approach to chemical degradation of Nafion membranes in fuel cells: modelling and predictions $\dagger$}

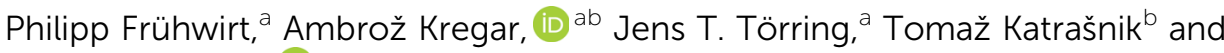 \\ Georg Gescheidt (iD *a
}

\begin{abstract}
The state of health of polyfluorinated sulfonic-acid ionomer membranes (e.g. Nafion ${ }^{\circledR}$ ) in lowtemperature proton exchange membrane fuel cells (LT-PEMFCs) is negatively influenced by degradation phenomena occurring during their operation. As a consequence, the performance and durability of the membrane are decreased. In this article, we focus on simulating and predicting chemical membrane degradation phenomena using a holistic zero-dimensional kinetic framework. The knowledge of chemical degradation mechanisms is widely spread. We have collected and evaluated an extensive set of chemical mechanisms to achieve a holistic approach. This yields a set of 23 coupled chemical equations, which provide the whole cause and effect chain of chemical degradation in LT-PEMFCs (based on the Fenton reaction between $\mathrm{Fe}^{2+}$ and $\mathrm{H}_{2} \mathrm{O}_{2}$ via the attack of hydroxyl radicals on the membrane, loss of ionomer moieties and emission of fluoride). Our kinetic framework allows the reproduction of experimentally accessible data such as fluoride emission rates and concentrations of ionomer moieties (from both in situ and ex situ tests). We present an approach, which allows estimations of the membrane lifetime based on fluoride emission rates. In addition, we outline the demetallation of $\mathrm{Fe}-\mathrm{N}-\mathrm{C}$ catalysts as a source of additional harmful iron species, which accelerate chemical membrane degradation. To demonstrate the expandability and versatility of the kinetic framework, a set of five chemical equations describing the radical scavenging properties of cerium agents is coupled to the main framework and its influence on membrane degradation is analysed. An automated solving routine for the system of coupled chemical equations on the basis of the chemical kinetic simulation tool COPASI has been developed and is freely accessible online (http://ptc-pc-139.tugraz.at/ cgi-bin/Membrane_Degradation/).
\end{abstract}

\section{Introduction}

In 2014, two-thirds of the world's total carbon dioxide emissions originated from the industry, electricity/heat and transport sectors. In the US and Europe, transportation accounted for about one-third of the total greenhouse gas emissions in that year. ${ }^{1}$ Approaches to tackle the decarbonisation in this sector are under development or even commercialised - e.g. hybrid electric vehicles (combination of conventional internal combustion engine and electric power engine), battery electric

\footnotetext{
${ }^{a}$ Institute of Physical and Theoretical Chemistry, Graz University of Technology, Stremayrgasse 9, 8010 Graz, Austria. E-mail: g.gescheidt-demner@tugraz.at

${ }^{b}$ Faculty of Mechanical Engineering, University of Ljubljana, Aškerčeva 6 , 1000 Ljubljana, Slovenia

$\dagger$ Electronic supplementary information (ESI) available: General scheme of the used automated solving routine, examples for input and output files, implementation of the model in Mathematica, Mathematica script. See DOI: 10.1039/ c9ср04986j
}

vehicles, fuel cell electric vehicles and fuel cell hybrid electric vehicles. Except for hybrid electric vehicles, they do not produce pollutants during operation. Provided that the electric power or fuel is produced in an ecologically sound manner from renewable sources, they can provide a $\mathrm{CO}_{2}$ neutral means of transportation. Vehicles powered by fuel cells (FCs) are superior in comparison to those relying on batteries when it comes to range and time required for recharging. However, the fuel cell technology suffers from a different type of problem - the restricted durability of the fuel cell components such as the membrane and the catalyst, and hence a limited long-term reliability of the fuel cells. ${ }^{2-4}$

One of the most frequently used types of FCs in the automotive sector are proton exchange membrane fuel cells (PEMFCs) operated at temperatures between $60{ }^{\circ} \mathrm{C}$ and $100{ }^{\circ} \mathrm{C} .{ }^{2,5}$ These lowtemperature PEMFCs usually comprise a polyfluorinated sulfonicacid (PFSA) ionomer as the membrane (e.g. Nafion $\left.{ }^{\circledR}\right)$. The chemical composition of Nafion ${ }^{\circledR}$ is depicted in Fig. 1. Due to the 


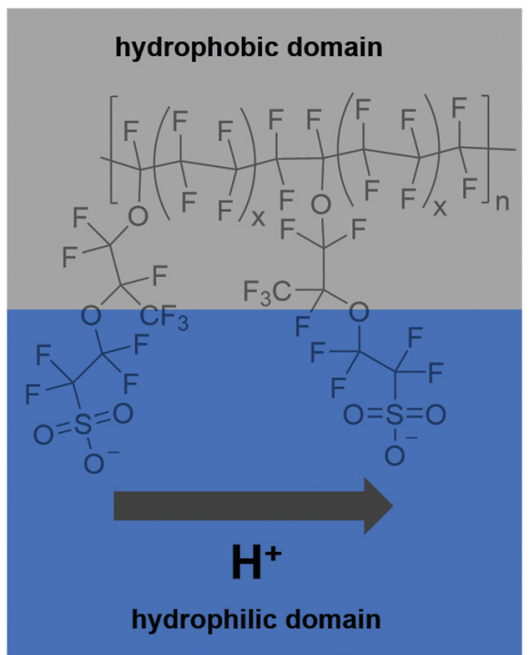

Fig. 1 Chemical composition of Nafion ${ }^{\mathbb{R}} 117(x=6.5)$. The protons are conducted in the hydrophilic domain (blue box) while the hydrophobic backbone (grey box) ensures mechanical stability of the membrane.

amphiphilic nature of the membrane, the conduction of the protons from the anode to the cathode side is ensured. This function is indispensable for the overall functionality of the fuel cell system. Thus, all degradation processes affecting the membrane reduce the efficiency of the fuel cell and considerably impact the reliability and durability of the system as a whole..$^{5-7}$

Membrane integrity is affected by chemical, thermal and mechanical degradation. ${ }^{8}$ Here, we focus on the chemical membrane degradation in low-temperature PEMFCs. An excellent discussion of various degradation phenomena can be found in the reviews by Borup et al., ${ }^{6}$ Kusoglu and Weber ${ }^{7}$ as well as Zaton et al. ${ }^{5}$ Many mechanisms and the corresponding chemical equations ${ }^{9-13}$ and kinetic details ${ }^{14-28}$ have been reported. Based on that, several chemical degradation models ${ }^{29-36}$ have been already presented. This knowledge, however, is spread in physically, chemically and technologically oriented context. Here we present an extensive picture of chemical degradation combining established data to describe chemical conversions in a Nafion ${ }^{\mathbb{B}}$ membrane. We use a zerodimensional (OD) chemical reactor model comprising a set of 23 coupled chemical equations. This powerful model allows monitoring and prediction of experimentally accessible data like time traces of chemical species involved ${ }^{33}$ and fluoride emission rates (FERs) ${ }^{35-37}$ Furthermore, we discuss the implications of iron containing ORR catalysts ${ }^{38-40}$ for membrane degradation and the use of cerium agents ${ }^{41-47}$ as radical scavengers to protect the chemical integrity of the membrane.

\section{Modelling approach}

Our kinetic framework and the assumptions of the model are based on fragmented knowledge spread across several chemical and technical publications. Accordingly, we, in the first instance, provide an overview of the state-of-the-art in terms of chemical membrane degradation.

\section{Formation of radical species}

Experimental evidence that radical species are formed during the operation of the fuel cell was presented by Panchenko et $a l^{48}$ By operating a miniature fuel cell within an electron paramagnetic resonance (EPR) spectrometer, radical species which arose from the electrode carbon material were detected. A similar setup was used by Danilczuk et al. ${ }^{49}$ to detect reactive oxygen species (ROS) such as hydroxyl $\left({ }^{\circ} \mathrm{OH}\right)$, hydroperoxyl $\left({ }^{\bullet} \mathrm{OOH}\right)$ and additionally, hydrogen $\left({ }^{\bullet} \mathrm{H}\right)$ and membranederived radical fragments after capturing them with a spin-trap.

The mechanism behind the formation of these species is a matter of debate. Under typical operation conditions oxygen is reduced at the cathode in the oxygen reduction reaction (ORR). This can happen via different reaction routes - either a direct reduction involving 4 electrons (eqn (1)) or two consecutive twoelectron reductions (eqn (2) and (3)) forming hydrogen peroxide $\left(\mathrm{H}_{2} \mathrm{O}_{2}\right)$ as an intermediate: ${ }^{50,51}$

$$
\begin{gathered}
\mathrm{O}_{2}+4 \mathrm{e}^{-}+4 \mathrm{H}^{+} \rightleftarrows 2 \mathrm{H}_{2} \mathrm{O} \quad E^{0}=1.229 \mathrm{~V} \\
\mathrm{O}_{2}+2 \mathrm{e}^{-}+2 \mathrm{H}^{+} \rightleftarrows \mathrm{H}_{2} \mathrm{O}_{2} \quad E^{0}=0.695 \mathrm{~V} \\
\mathrm{H}_{2} \mathrm{O}_{2}+2 \mathrm{e}^{-}+2 \mathrm{H}^{+} \rightleftarrows 2 \mathrm{H}_{2} \mathrm{O} \quad E^{0}=1.763 \mathrm{~V}
\end{gathered}
$$

By equipping the membrane with Pt microelectrodes, Liu and Zuckerbrod ${ }^{52}$ were able to detect micromolar concentrations of $\mathrm{H}_{2} \mathrm{O}_{2}$ in the membrane during operation $\left(60{ }^{\circ} \mathrm{C}\right.$, open circuit voltage (OCV) conditions). Nevertheless, the formation of $\mathrm{H}_{2} \mathrm{O}_{2}$ is not confined to the cathode side. During operation of the fuel cell, oxygen can diffuse to the anode side, where $\mathrm{H}_{2} \mathrm{O}_{2}$ is also formed. A dependence of $\left[\mathrm{H}_{2} \mathrm{O}_{2}\right]$ on the thickness of the membrane was also observed - the thinner the membrane, the higher $\left[\mathrm{H}_{2} \mathrm{O}_{2}\right]$. This is most likely connected to the increased $\mathrm{O}_{2}$ crossover in thinner membranes. ${ }^{52}$ Similar results were obtained by Chen and Fuller. ${ }^{53}$ Shah et al. ${ }^{30}$ calculated $\left[\mathrm{H}_{2} \mathrm{O}_{2}\right]$ in the membrane for different operating conditions (voltage, temperature) - the highest values were found to be near or in the anode catalyst layer (up to $3.5 \mathrm{mM}$ ) while the value on the cathode side stayed below $0.5 \mathrm{mM}$ for $60{ }^{\circ} \mathrm{C}$ and OCV. Simulations by Wong and Kjeang ${ }^{34}$ indicate $\left[\mathrm{H}_{2} \mathrm{O}_{2}\right]$ of about $1.5 \mathrm{mM}$ in the membrane under OCV conditions. Inaba et al. ${ }^{54}$ supposed that due to the elevated boiling point of $\mathrm{H}_{2} \mathrm{O}_{2}$ compared to that of water the concentration of $\mathrm{H}_{2} \mathrm{O}_{2}$ could be increased when the fuel cell is operated under low humidity conditions.

$\mathrm{H}_{2} \mathrm{O}_{2}$ is not a strong enough oxidant to attack the ionomer directly and is, therefore, characterised by a relatively long lifetime within the fuel cell. This leads to a diffusion length of $\mathrm{H}_{2} \mathrm{O}_{2}$ in the $\mathrm{mm}$ to $\mathrm{cm}$ range, which is large compared to the typical membrane thickness (in the $\mu \mathrm{m}$ range). ${ }^{31}$ Under certain conditions, though, $\mathrm{H}_{2} \mathrm{O}_{2}$ is highly active in oxidizing organic substrates (like the fuel cell membrane) - a fact which has been known for more than hundred years. In 1894, Fenton discovered that a mixture of $\mathrm{H}_{2} \mathrm{O}_{2}$ and ferrous salts effectively reacts with tartaric acid. ${ }^{55}$ The reaction between ferrous ions and $\mathrm{H}_{2} \mathrm{O}_{2}$ is known as the Fenton reaction: ${ }^{56,57}$

$$
\mathrm{Fe}^{2+}+\mathrm{H}_{2} \mathrm{O}_{2}+\mathrm{H}^{+} \rightleftarrows \mathrm{Fe}^{3+}+\cdot \mathrm{OH}+\mathrm{H}_{2} \mathrm{O}
$$


Furthermore, the emerging species are also involved in further redox reactions leading to the formation of additional ROS and redox recycling of the active ferrous ion: ${ }^{58,59}$

$$
\begin{gathered}
\mathrm{Fe}^{3+}+\mathrm{H}_{2} \mathrm{O}_{2} \rightleftarrows \mathrm{Fe}^{2+}+\cdot \mathrm{OOH}+\mathrm{H}^{+} \\
\mathrm{Fe}^{2+}+\cdot{ }^{\bullet} \mathrm{OH}+\mathrm{H}^{+} \rightleftarrows \mathrm{Fe}^{3+}+\mathrm{H}_{2} \mathrm{O} \\
\mathrm{Fe}^{2+}+\cdot{ }^{\bullet} \mathrm{OOH}+\mathrm{H}^{+} \rightleftarrows \mathrm{Fe}^{3+}+\mathrm{H}_{2} \mathrm{O}_{2} \\
\mathrm{Fe}^{3+}+{ }^{\bullet} \mathrm{OOH} \rightleftarrows \mathrm{Fe}^{2+}+\mathrm{H}^{+}+\mathrm{O}_{2}
\end{gathered}
$$

Pozio et al. ${ }^{57}$ demonstrated that stainless steel (type SS316L) end plates serve as a source of iron contaminants in fuel cells. When using aluminium (Al) end plates in operando the average fluoride concentration measured in the cathode water was only about $1 / 10$ of that with stainless steel end plates. For the anode side a reduction in fluoride emission by $60 \%$ was observed when switching from SS316L end plates to $\mathrm{Al}$ end plates. In addition, a decrease in Fe concentration in the cathode water from about $600 \mathrm{ppb}$ (for SS316L) to less than $100 \mathrm{ppb}$ (for $\mathrm{Al}$ ) was also evident. For the anode water in the case of SS316L end plates, a Fe concentration of $925 \mathrm{ppb}$ was determined. Papadias et $a l^{60}$ found a total ion release rate of about $0.4 \mu \mathrm{g} \mathrm{cm}^{-2} \mathrm{~h}^{-1}$ in the range of 0 to $1 \mathrm{~V}$ for stainless steel (type SS316L) bipolar plates. $90 \%$ of all released ions were $\mathrm{Fe}$ and $\mathrm{Ni}$.

Not only the end plates used in fuel cells, but also the membrane material might contribute to the contamination of the fuel cell with iron. Coms et al. ${ }^{61}$ estimated the BOL (begin of life) concentration of iron to be 5 to $10 \mathrm{ppm}$. Liu et al. ${ }^{62}$ attributed an iron concentration of $5 \mathrm{ppm}$ to an as-received NE112 ionomer. Due to the anionic nature of the sulfonic acid head groups Nafion ${ }^{\circledR}$ is known to immobilise iron ions, ${ }^{63}$ which could even lead to an accumulation of iron within the membrane during operation. Andersen ${ }^{64}$ observed in swellingdehydration experiments with Nafion ${ }^{\circledR} 212$ that the ionomer tends to have higher selectivity for high-valence cations (like $\mathrm{Fe}^{3+}$, which then replace protons and negatively impact the proton conductivity of the ionomer and its thermochemical properties. $^{7}$

The observation that ferrous ions accelerate the membrane degradation is actively employed in ex situ degradation tests (so-called Fenton tests) ${ }^{65-67}$ and also in situ tests ${ }^{41,62}$ to assess the durability of membrane materials. Other transition metal ions such as $\mathrm{Ti}^{3+66} \mathrm{Co}^{2+68,69}$ or $\mathrm{Cu}^{+70-72}$ are also known to convert $\mathrm{H}_{2} \mathrm{O}_{2}$ to $\mathrm{ROS}$ like ${ }^{\bullet} \mathrm{OH}$ and ${ }^{\bullet} \mathrm{OOH}$.

In addition to the formation of radical species via hydrogen peroxide as an intermediate, radicals can also be formed directly on platinum surfaces. Density functional theory (DFT) calculations by Atrazhev et $a .^{73}$ show that formation of ${ }^{\bullet} \mathrm{OH}$ might be possible under conditions where the oxygen reduction is prevented by the presence of other adsorbed species. In close vicinity to other Pt particles (e.g. in the electrode) ${ }^{\bullet} \mathrm{OH}$ might be destroyed effectively before reaching the polymer membrane, as for the adsorption of hydroxyl radicals no activation barrier at any potential is calculated. ${ }^{73}$ Despite the decreased selectivity for ${ }^{\bullet} \mathrm{OH}$ to attack the membrane in Pt-rich environments,
Pt particles deposited into a PFSA membrane increased the FER compared to the untreated membrane. ${ }^{74}$ Whether dispersed platinum particles catalyse the formation of radicals or act as scavengers and protect the membrane from radical attack is a function of the metal loading in the membrane. At higher platinum levels (30 to $50 \mathrm{~mol} \%$ ) radical scavenging is predominant while at $10 \mathrm{~mol} \%\left(n_{\mathrm{Pt}} / n_{\text {membrane }}\right)$ this is outweighed by the generation of radicals. ${ }^{75}$

Due to the sluggish kinetics of the ORR, high amounts of Pt or Pt alloys need to be used at the cathode side to efficiently catalyse the oxygen reduction. To reduce or avoid the use of the precious noble metal, alternatives such as non-precious metal catalysts (NPMCs) have been developed. Among these are metal/nitrogen/carbon ( $\mathrm{M}-\mathrm{N}-\mathrm{C})$ catalysts, where the metal is mostly iron. Although they are highly active in catalysing the oxygen reduction reaction, there is still room for improvement in terms of durability and stability. ${ }^{38}$ A lifetime-limiting factor for $\mathrm{Fe}-\mathrm{N}-\mathrm{C}$ catalysts is the $\mathrm{Fe}$ demetallation in acidic media (such as the PEMFC). Depending on the synthesis of the catalyst, inactive $\mathrm{Fe}$ particles (in addition to the active $\mathrm{FeC}_{x} \mathrm{~N}_{y}$ centres) remain at the surface, which cannot be completely removed by acid washing and lead to iron leaching in operando. ${ }^{39}$ A recent study by Chenitz et al. ${ }^{40}$ showed that demetallation at the catalytic $\mathrm{Fe}-\mathrm{N}_{4}$ centres of a Fe-N-C catalyst $\left(\mathrm{NC} \_\mathrm{Ar}+\mathrm{NH}_{3}\right)$ due to the flux of water in the micropores of the catalyst is also possible providing an additional source of iron species.

\section{Overview of degradation mechanisms}

Regardless of the formation mechanism of radical species, Nafion ${ }^{\circledR}$ ionomers offer in principle four different points of attack for ${ }^{\bullet} \mathrm{OH}$ or ${ }^{\bullet} \mathrm{H}$ : (1) carboxylic acid (-COOH) end groups in the main chain (unzipping mechanism), (2) the sulfonic acid head groups $\left(-\mathrm{SO}_{3} \mathrm{H}\right),(3)$ ether groups in the side chain and finally (4) the tertiary carbons found in both side chain and main chain (Fig. 2). ${ }^{5}$

Main chain degradation mechanism. The main chain degradation mechanism according to Curtin et al. ${ }^{9}$ relies on fragile end groups (e.g. carboxylic acid moieties) ${ }^{76}$ in the backbone (BB) of Nafion ${ }^{\circledR}$ formed during the manufacture of the

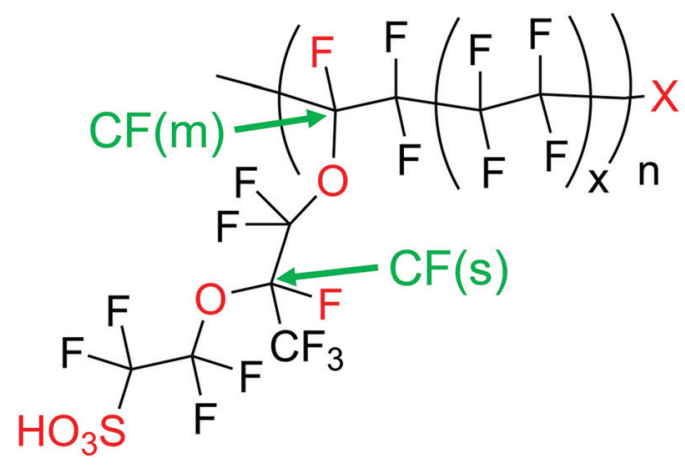

Fig. 2 Chemical composition of Nafion ${ }^{\circledR} 117(x=6.5)$ as an example for a commonly used PFSA. The points of attack for radical species are marked in red and the green labels represent the tertiary carbon atoms. $X$ stands for a weak end group like $-\mathrm{COOH}$. 


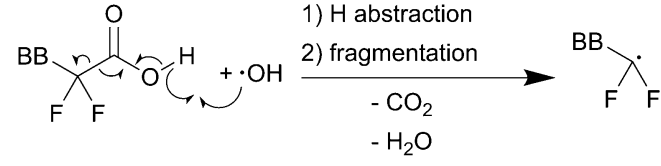

$$
\lambda_{\mathrm{F}}^{\mathrm{BB}}+\cdot \mathrm{OH}
$$
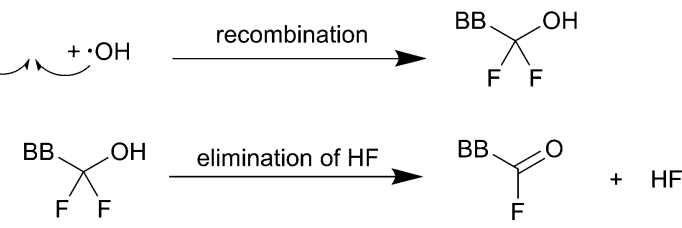

$Y_{F}^{\mathrm{BB}} \mathrm{O}$
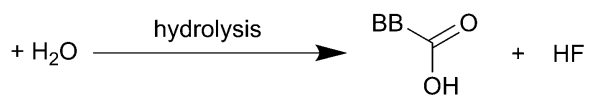

Scheme 1 Main chain degradation mechanism as proposed by Curtin et al. ${ }^{9}$ BB represents the backbone of the PFSA ionomer. Single barbed arrows indicate the formation of new chemical bonds and homolytic cleavage of bonds.

membrane (see Scheme 1). The mechanism is initiated by an abstraction of the carboxylic hydrogen by ${ }^{\bullet} \mathrm{OH}$ followed by the fragmentation of the intermediate radical species to $\mathrm{CO}_{2}$ and $\mathrm{BB}-\mathrm{CF}_{2}{ }^{\bullet}$. After recombination with another ${ }^{\bullet} \mathrm{OH}$ the formed primary alcohol undergoes elimination of hydrogen fluoride (HF). The product (acid fluoride) is prone to hydrolysis to give another carboxylic acid moiety and the cycle restarts. For each degradation cycle (loss of one - $\mathrm{COOH}$ moiety and conversion of the adjacent $\mathrm{CF}_{2}$ unit to a new $-\mathrm{COOH}$ group) two ${ }^{\circ} \mathrm{OH}$ are needed to form two HF molecules. Hence, a linear dependence of fluoride emission on the number of $\mathrm{COOH}$ groups can be expected here, which is corroborated by the results obtained from ex situ Fenton tests by Schwiebert et al. ${ }^{77}$ Zhou et al. ${ }^{78}$ performed degradation experiments with small molecule analogues for Nafion ${ }^{\circledR}$ and found that model compounds with carboxylic acid terminals degrade one order of magnitude faster than molecules without $\mathrm{COOH}$ groups.

Thermodynamic driving force for hydrogen abstraction is the formation of a strong $\mathrm{O}-\mathrm{H}$ bond (namely that of $\mathrm{H}_{2} \mathrm{O}$ ) with an experimental bond enthalpy $\left(\Delta H_{298}\right)$ of $497 \mathrm{~kJ} \mathrm{~mol}^{-1}$ while cleaving the weaker $\mathrm{O}-\mathrm{H}$ bond of the carboxylic acid (computed bond enthalpy of $426 \mathrm{~kJ} \mathrm{~mol}^{-1}$ for $\left.\mathrm{CF}_{3} \mathrm{COOH}\right) .{ }^{10}$

The number of unprotected groups can be greatly reduced by chemical stabilisation techniques (e.g. conversion of $-\mathrm{COOH}$ to $-\mathrm{CF}_{3}$ by treatment with fluorine).$^{9,79}$ Cipollini ${ }^{79}$ found lower FERs for treated Nafion ${ }^{\circledR}$ membranes in Fenton degradation tests. But the same author also observed that in operando $\left(90{ }^{\circ} \mathrm{C}, 30 \%\right.$ relative humidity, anode: $\mathrm{H}_{2}+5 \% \mathrm{O}_{2}$, cathode: $\mathrm{O}_{2}$ ), these differences in FER values between untreated and treated ionomers vanished. These experimental observations indicate the presence of other degradation mechanisms under fuel cell conditions. ${ }^{79}$

Further experimental evidence for the unzipping mechanism was presented by Danilczuk et al. ${ }^{80}$ The stability of different polyfluorinated membranes (Nafion ${ }^{\circledR}$, stabilised Nafion ${ }^{\circledR}, 3 \mathrm{M}$ ionomer and Aquivion ${ }^{\circledR}$ ) was investigated by spin-trapping EPR spectroscopy. ${ }^{\bullet} \mathrm{OH}$ was generated by photolysis of $\mathrm{H}_{2} \mathrm{O}_{2}$ in the presence of the ionomers and then trapped by using DMPO
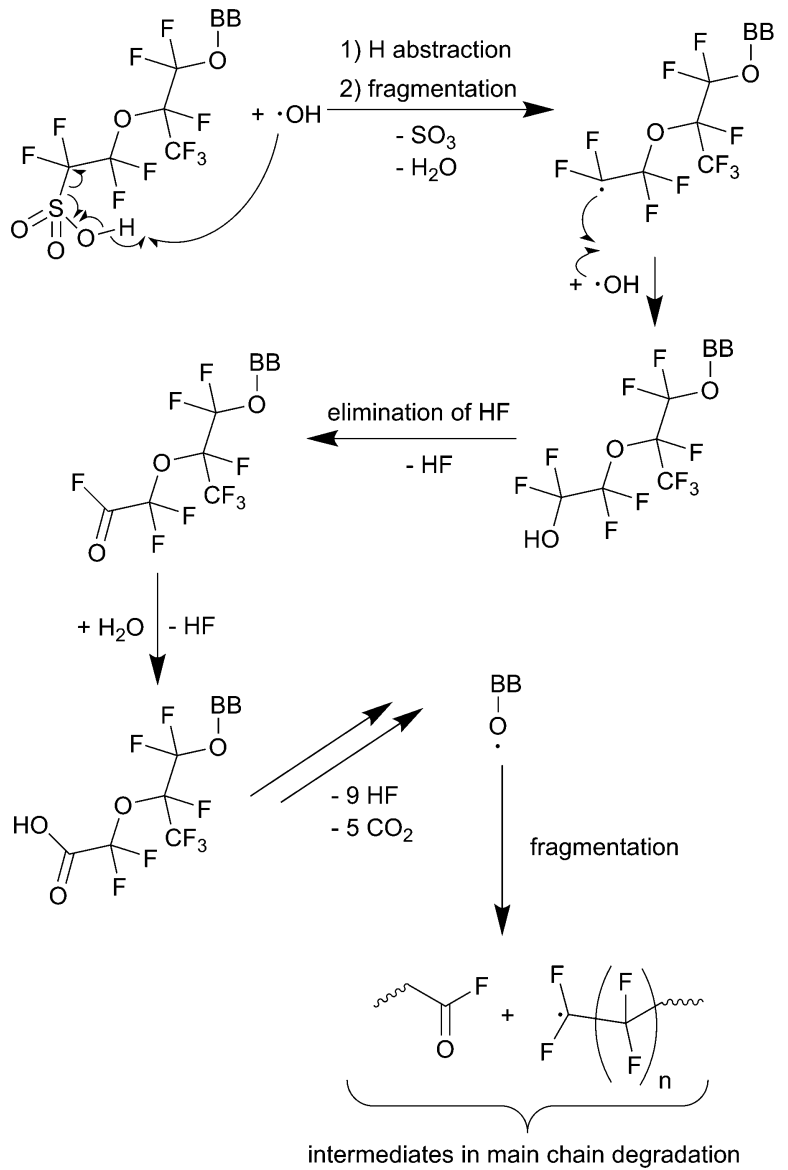

Scheme 2 Side chain degradation mechanism as proposed by Ghassemzadeh et al. $^{11}$ BB represents the backbone of the PFSA ionomer. Single barbed arrows indicate the formation of new chemical bonds and homolytic cleavage of bonds.

(5,5-dimethyl-1-pyrroline $\mathrm{N}$-oxide). Besides the detection of the expected DMPO-OH radical adduct, carbon-centred radical intermediates were also established for all ionomers. For the $3 \mathrm{M}$ and the Aquivion ${ }^{\circledR}$ ionomer it was concluded that the observed radical adduct is a result of an attack of ${ }^{\bullet} \mathrm{OH}$ on the $\mathrm{COOH}$ moieties of the polymers. For Nafion ${ }^{\circledR}$ and stabilised Nafion ${ }^{\circledR}$ another carbon-centred radical species was detected, which was attributed to a side-chain-derived radical. ${ }^{80}$

Attack at the sulfonic acid moiety. Attack on the sulfonic acid moiety located in the side chain (SC) was proposed by Ghassemzadeh et al. ${ }^{11}$ (Scheme 2) based on the detection of the end-chain radical $\mathrm{SC}-\mathrm{OCF}_{2} \mathrm{CF}_{2}{ }^{\bullet}$ upon $\mathrm{UV}$ irradiation of Nafion ${ }^{\circledR}$ in the presence of $\mathrm{Fe}(\mathrm{III})$ or $\mathrm{Fe}(\mathrm{II})$ and $\mathrm{H}_{2} \mathrm{O}_{2} \cdot{ }^{81,82}$ DFT calculations for $\mathrm{CF}_{3} \mathrm{SO}_{3} \mathrm{H}$ show that a bond enthalpy of only $236 \mathrm{~kJ} \mathrm{~mol}^{-1}$ can be ascribed to the $\mathrm{C}-\mathrm{S}$ bond rendering it the weakest bond among all bonds in the side chain. ${ }^{10}$

The $\mathrm{O}-\mathrm{H}$ bond of the sulfonic group involved in the first reaction in Scheme 2 features a bond enthalpy of $406 \mathrm{~kJ} \mathrm{~mol}^{-1}$ (computed for $\left.\mathrm{CF}_{3} \mathrm{SO}_{3} \mathrm{H}\right)^{10}$ making the hydrogen abstraction by - $\mathrm{OH}$ energetically favourable. The following steps finally lead to an unstable alkoxy radical $\left(\mathrm{BB}-\mathrm{O}^{\bullet}\right)$ which is then inevitably converted to an acid fluoride and $\mathrm{a} \mathrm{BB}-\mathrm{CF}_{2}{ }^{\bullet}$ radical - both 


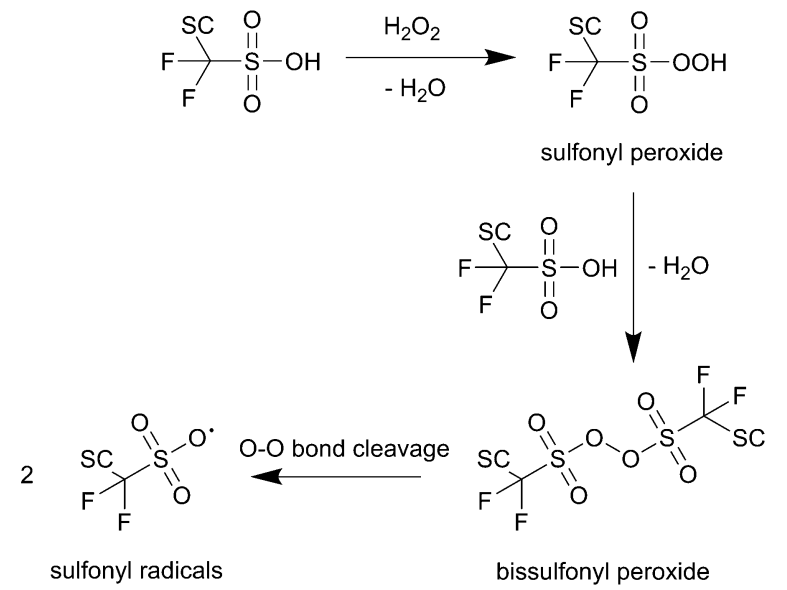

Scheme 3 Formation of sulfonyl radicals via peroxide intermediates as proposed by Coms. ${ }^{10} \mathrm{SC}$ represents the side chain of the ionomer.

involved in the main chain unzipping process, too. As an intermediate in the first step a sulfonyl radical (SC$\mathrm{OCF}_{2} \mathrm{CF}_{2} \mathrm{SO}_{3}{ }^{\bullet}$ ) is postulated, ${ }^{81}$ which can also be generated by another mechanism involving $\mathrm{H}_{2} \mathrm{O}_{2}$ as an oxidant for the sulfonic acid (see Scheme 3).$^{10}$ The intermediate sulfonyl peroxide can react with another sulfonic acid to form bissulfonyl peroxide, whose $\mathrm{O}-\mathrm{O}$ bond is finally cleaved to yield two sulfonyl radicals. Again, the cleavage of the weak $\mathrm{C}-\mathrm{S}$ bond leads to $\mathrm{SC}-\mathrm{OCF}_{2} \mathrm{CF}_{2}{ }^{\bullet}$ and $\mathrm{SO}_{3}{ }^{10}$

Ether cleavage mechanism. Not only the sulfonic acid head group is susceptible to radical attacks, also the ether moiety in the side chain should be considered as a point of attack by radicals, as proposed by Ghassemzadeh et al. ${ }^{12,13} \mathrm{~A}$ Nafion ${ }^{\circledR}$ 211 membrane was subjected to a Fenton test and the concentrations of the fluorine-containing membrane units were monitored by ${ }^{19} \mathrm{~F}$ MAS NMR (magic angle spinning nuclear magnetic resonance) spectroscopy. The highest decrease in concentration (up to $15 \%$ over $48 \mathrm{~h}$ ) was observed for the two $\mathrm{CF}_{2}$ groups adjacent to the hydrophilic head group. ${ }^{12}$ Similar results were obtained when using an electron beam to irradiate an aqueous solution of $\mathrm{H}_{2} \mathrm{O}_{2}$ in the presence of Nafion ${ }^{\circledR} 211 .{ }^{13}$ This mechanism is further supported by EPR investigations by Danilczuk et al. showing that ionomers with shorter side chains (3M and Aquivion ${ }^{\mathbb{R}}$ ) are characterised by a higher stability towards the radical attack of ${ }^{\bullet} \mathrm{OH}$ compared to (stabilised) Nafion ${ }^{\mathrm{B}} .80$

The mechanism depicted in Scheme $4^{13}$ starts with a radicalinitiated ether cleavage on the side chain, which can happen from both sides of the ether oxygen leading to different side chain fragments, which could be detected by ${ }^{19} \mathrm{~F}$ NMR. By using attenuated total reflection Fourier transform infrared spectroscopy (ATR-FTIR) the presence of $\mathrm{C}=\mathrm{O}$ bonds could be established. ${ }^{13}$

Attack at the tertiary carbons. So far, all discussed degradation procedures rely on the attack of ROS. Beyond that, ${ }^{\bullet} \mathrm{OH}$ also tends to react with other $\mathrm{H}$ donors such as molecular hydrogen giving rise to hydrogen radicals: ${ }^{83}$

$$
\mathrm{H}_{2}+\cdot \mathrm{OH} \rightleftarrows \cdot \mathrm{H}+\mathrm{H}_{2} \mathrm{O}
$$

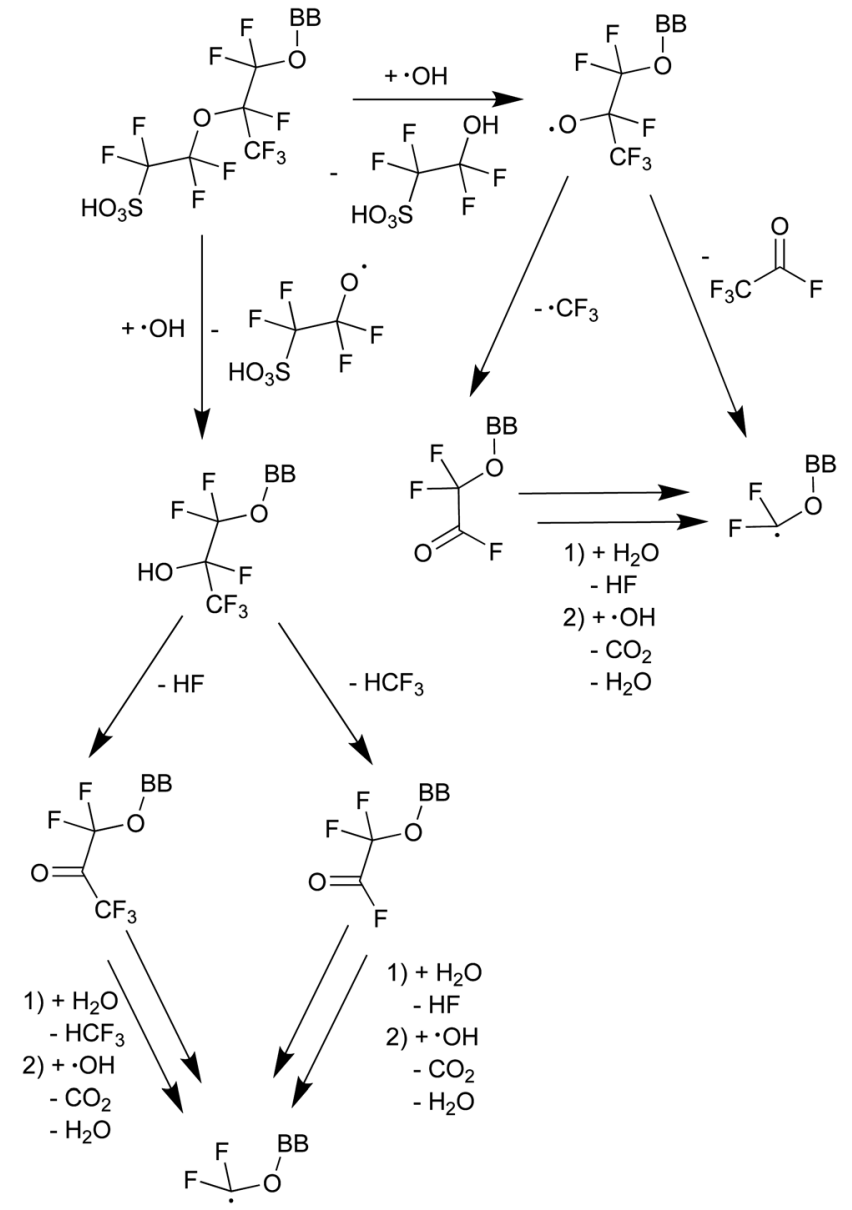

Scheme 4 Proposed mechanism of ether cleavage with subsequent fragmentation and side-chain unzipping. ${ }^{13} \mathrm{BB}$ represents the backbone of the PFSA ionomer.

As ${ }^{\bullet} \mathrm{H}$ is produced along with ROS like ${ }^{\bullet} \mathrm{OH}$ and ${ }^{\bullet} \mathrm{OOH}$ under fuel cell conditions, ${ }^{49}$ it is difficult to study the impact of ${ }^{\bullet} \mathrm{H}$ on membrane degradation in situ. Ghassemzadeh et al. ${ }^{13}$ were able to generate ${ }^{\circ} \mathrm{H}$ selectively by irradiating an aqueous $\mathrm{H}_{2} \mathrm{SO}_{4}$ solution with an electron beam in the presence of Nafion ${ }^{\mathbb{R}}$ 211. Their results indicate that the points of attack for ${ }^{\circ} \mathrm{H}$ are the tertiary C-F bonds located on the main and side chain (see Fig. 2). Based on that, a degradation mechanism involving just ${ }^{-} \mathrm{H}$ was proposed. In principle, both tertiary $\mathrm{C}-\mathrm{F}$ bonds are points of attack for the highly reactive ${ }^{\bullet} \mathrm{H}$ which finally leads to the fragmentation of the side chain at the tertiary carbons. ${ }^{13}$ These findings are corroborated by DFT calculations ${ }^{10,84}$ which demonstrate that the bond enthalpy of C-F bonds is the lowest for tertiary carbons. Based on the bond strengths (primary $\mathrm{C}-\mathrm{F}: \approx 520 \mathrm{~kJ} \mathrm{~mol}^{-1}$; secondary $\mathrm{C}-\mathrm{F}: \approx 480 \mathrm{~kJ} \mathrm{~mol}^{-1}$; tertiary $\left.\mathrm{C}-\mathrm{F}: \approx 440 \mathrm{~kJ} \mathrm{~mol}^{-1}\right)$ and $\mathrm{HF}\left(571 \mathrm{~kJ} \mathrm{~mol}^{-1}\right)$ fluorine abstractions from any position of the Nafion ${ }^{\mathbb{R}}$ structure should be thermochemically favourable, though only abstractions at secondary and tertiary C-F bonds are estimated to be kinetically feasible. ${ }^{10}$

One should bear in mind that this mechanism is strictly valid only in a system where just ${ }^{\bullet} \mathrm{H}$ as radical species is present. Under fuel cell conditions, a synergetic cooperation 
of the ROS and ${ }^{\bullet} \mathrm{H}$ should be expected resulting in a more complicated degradation process. ${ }^{\cdot} \mathrm{H}$ might activate the side chains for following attacks by ROS.

\section{Previously published modelling approaches}

On the basis of the degradation mechanisms discussed above several modelling approaches comprising membrane degradation phenomena ${ }^{29-36}$ have been published. The model by Xie and Hayden ${ }^{29}$ does not concentrate on the formation of radical species; yet it is possible to distinguish between two possibilities for initiation of PFSA degradation - either at the weak end groups of the main chain or at the side chains. In addition, it is impossible to deduce FERs from the model. A kinetic framework to describe the formation of $\mathrm{H}_{2} \mathrm{O}_{2}$ and ROS was provided in an extensive one-dimensional model of Shah et al. ${ }^{30}$ Gubler et $a l .^{31}$ presented a more comprehensive kinetic framework. With their zero-dimensional chemical reactor model comprising rate constants at room temperature they were able to estimate the quasi-steady state concentrations of ${ }^{\bullet} \mathrm{H}, \bullet^{\bullet} \mathrm{OH}$ and -OOH. FERs for ex situ Fenton and under fuel cell operation conditions after extrapolation to $90{ }^{\circ} \mathrm{C}$ were predicted. For the Fenton tests the agreement of the calculated FER with literature data was satisfying; however, the FER for in situ conditions was 2 to 3 orders of magnitude lower than the experimental results.

Both the models of Shah et al. ${ }^{30}$ and Gubler et al. ${ }^{31}$ rely on the main chain unzipping mechanism as the major membrane degradation mechanism, yet improved chemical posttreatment effectively decreased the number of weak end groups in PFSA ionomers. ${ }^{79}$ Ghelichi et al..$^{32}$ used a similar kinetic framework to that of Gubler et al. ${ }^{31}$ (rate constants at $80{ }^{\circ} \mathrm{C}$ instead of room temperature) in their coarse-grained degradation model dividing the PFSA structure into backbone, trunk and head group units. Radical concentrations were calculated following a steady-state approach neglecting the effects of the PFSA ionomer as a sink for radical species. The rate constants for the unzipping reaction and head group dissociation were derived from fitting analytical expressions to experimental data. For both the unzipping and the head group dissociation rate constant a good agreement with rate constants for model compounds determined by Dreizler and Rodune ${ }^{20}$ was achieved. However, the rate constant for head group dissociation is dependent on the data used for fitting. ${ }^{32}$

Similar to Ghelichi et al. ${ }^{32}$ the approach by Wong and Kjeang $^{33}$ is also based on the degradation of the side chain and features the radical ether cleavage (shown in Scheme 4) as the initiation step of ionomer destruction. Even though the kinetic framework for radical formation only comprises the Fenton reaction and all reaction constants are given for room temperature, trends observed in in situ tests can be well reproduced with their model. The kinetic framework ${ }^{33}$ was expanded in a later publication by Wong and Kjeang. ${ }^{34}$ An analogue model was presented recently by Singh et al. ${ }^{35}$ being extended by regarding the temperature dependence of the Fenton reaction and an iron redox cycle, which is established by the reaction of ferric ions with hydrogen radicals.
A recent publication by Futter $e t$ al. ${ }^{36}$ features an extensive radical reaction framework similar to the ones already presented. ${ }^{30-32,34}$ Furthermore, the degradation reactions displayed in this model are based on the coarse-grained approach, ${ }^{32}$ with an excellent agreement with experimental data from accelerated stress tests.

\section{Modelling framework}

In the following paragraphs our modelling framework is described (for schematic explanation see Scheme 5), which merges and expands the hitherto published ones. ${ }^{30-36} \mathrm{~A}$ combination of ionomer degradation reactions ${ }^{33-35}$ (see Scheme 6) with basic radical chemistry ${ }^{14-28}$ leads to a system of 23 coupled chemical equations (see Table 1). This set of equations is then solved by an automatisation routine based on the freely available kinetic simulation program COPASI. ${ }^{85}$ This allows predictions of fluoride emission rates and concentration traces of ionomer moieties and degradation products.

Our model relies on the following assumptions:

1. An isotherm zero-dimensional chemical reactor for the ionomer membrane. This model is characterised by uniform distribution of all involved chemical species over the whole reaction volume, which is equal to the membrane volume. Hence, no diffusion of species is observed. For highly reactive species such as ${ }^{\circ} \mathrm{OH}$ diffusion can indeed be neglected, as diffusion length in the $\mathrm{nm}$ range is estimated, ${ }^{31}$ which is 3 orders of magnitude lower than the average thickness of the PFSA ionomer membrane. Once formed, the ${ }^{\bullet} \mathrm{OH}$ radicals react with other species in close vicinity, and thus the damage induced by the radical attack can be considered as highly localised.

2. Besides ${ }^{\bullet} \mathrm{OH}$, the generation of ${ }^{\bullet} \mathrm{OOH}$ and ${ }^{\bullet} \mathrm{H}$ is also covered in the model, though their involvement in chemical membrane degradation is neglected. Due to the relatively low enthalpy of the $\mathrm{O}-\mathrm{H}$ bond in $\mathrm{H}_{2} \mathrm{O}_{2}\left(366 \mathrm{~kJ} \mathrm{~mol}^{-1}\right)$ hydrogen abstraction from PFSA ionomers by ${ }^{\circ} \mathrm{OOH}$ radicals is thermodynamically highly unfavoured. ${ }^{10}$ Nevertheless, the possibility of a recombination of $\mathrm{OOH}$ with carbon-centred radicals formed during the degradation cannot be ruled out. Gubler et $a l .{ }^{31}$ argued that, despite the low steady-state concentration of ${ }^{\bullet} \mathrm{H}$ at room temperature in the presence of ionomer (2 orders of magnitude lower than $\left.{ }^{\bullet} \mathrm{OH}\right),{ }^{\bullet} \mathrm{H}$ might have a considerable effect on the membrane degradation; however due to the lack of kinetic data, its influence cannot be evaluated by the model.

3. The primary source of ROS is assumed to be the reactions of $\mathrm{H}_{2} \mathrm{O}_{2}$ and both the ferrous $\left(\mathrm{R}_{1}\right.$; Fenton reaction) and ferric ions $\left(\mathrm{R}_{2}\right)$ and to a small extent the homolytic cleavage of the $\mathrm{O}-\mathrm{O}$ bond in $\mathrm{H}_{2} \mathrm{O}_{2}\left(\mathrm{R}_{6}\right)$. All other sources of ROS and hydrogen radicals (e.g. formation at Pt particles ${ }^{73-75}$ ) are neglected in the model. In addition, the potential-dependent redox recycling of iron species ${ }^{34}$ in the membrane is not taken into account.

4. Although protons are involved in some of the chemical reactions, their rates are basically independent of the $\mathrm{pH}$. Accordingly, $\mathrm{pH}$ effects ${ }^{20}$ are not considered.

5 . We consider the changes in concentration due to the swelling of the ionomer membrane ${ }^{34}$ as negligible. 
MODELLING FRAMEWORK

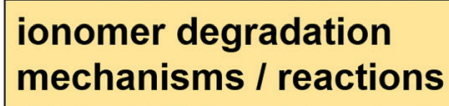

\section{basic radical chemistry \\ (ROS, $\cdot \mathrm{H})$}

model setup

\section{OD chemical reactor model (set of 23 coupled chemical equations)}

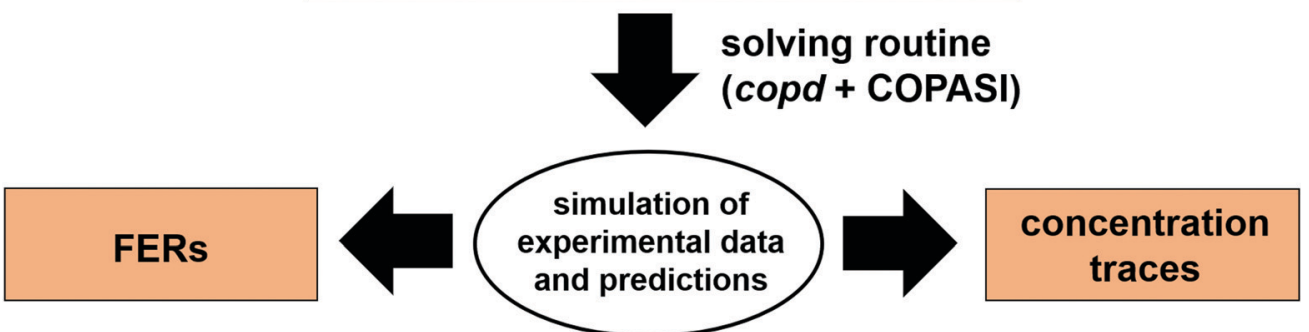

Scheme 5 Schematic drawing of the modelling framework presented in this article. lonomer degradation mechanisms/reactions ${ }^{33-35}$ (see Scheme 6 ) are combined with basic radical reactions of ROS and $\cdot \mathrm{H}^{14-28}$ to yield a zero-dimensional chemical reactor model comprising a set of coupled chemical equations. This system of differential equations is solved by a combination of the self-developed tool copd and freely available software COPASI. ${ }^{85}$ Fluoride emission rates and concentration traces (e.g. $\mathrm{HF}, \mathrm{CO}_{2}$, ionomer moieties) can be simulated and predicted.

6. For the $0 \mathrm{D}$ chemical reactor a constant concentration (steady-state) of $\mathrm{H}_{2} \mathrm{O}_{2}$ is assumed.

7. A constant total iron concentration $\left[\mathrm{Fe}^{x+}\right]=\left[\mathrm{Fe}^{2+}\right]+\left[\mathrm{Fe}^{3+}\right]$ within the reactor is assumed, unless otherwise stated.

8. Chemical degradation of the membrane generally starts at the side-chain and proceeds (up to seven $\mathrm{CF}_{2}$ groups) along the backbone (Scheme 6).

9. For $\mathrm{R}_{15}, \mathrm{R}_{16}$ and $\mathrm{R}_{17-23}$ it is assumed that the first step (i.e. the attack of the hydroxyl radical) is rate-determining, ${ }^{20,28,33}$ which leads to the rate laws given in Table 1 .
10. To account for the temperature-dependence of the rate constants, the Arrhenius approach (eqn (10)) is chosen. The necessary kinetic data are summarised in Table 1.

$$
k=A \mathrm{e}^{-\frac{E_{\mathrm{a}}}{R T}}
$$

The rate constants for $\mathrm{R}_{15}$ and $\mathrm{R}_{16}$ were estimated by Wong and Kjeang, ${ }^{33}$ and all other rate constants were obtained experimentally. ${ }^{14-28}$ For all ionomer degradation reactions $\left(\mathrm{R}_{14}-\mathrm{R}_{23}\right)$ the same (average) activation energy of $70 \mathrm{~kJ} \mathrm{~mol}^{-1}$ was assumed. ${ }^{31,86}$
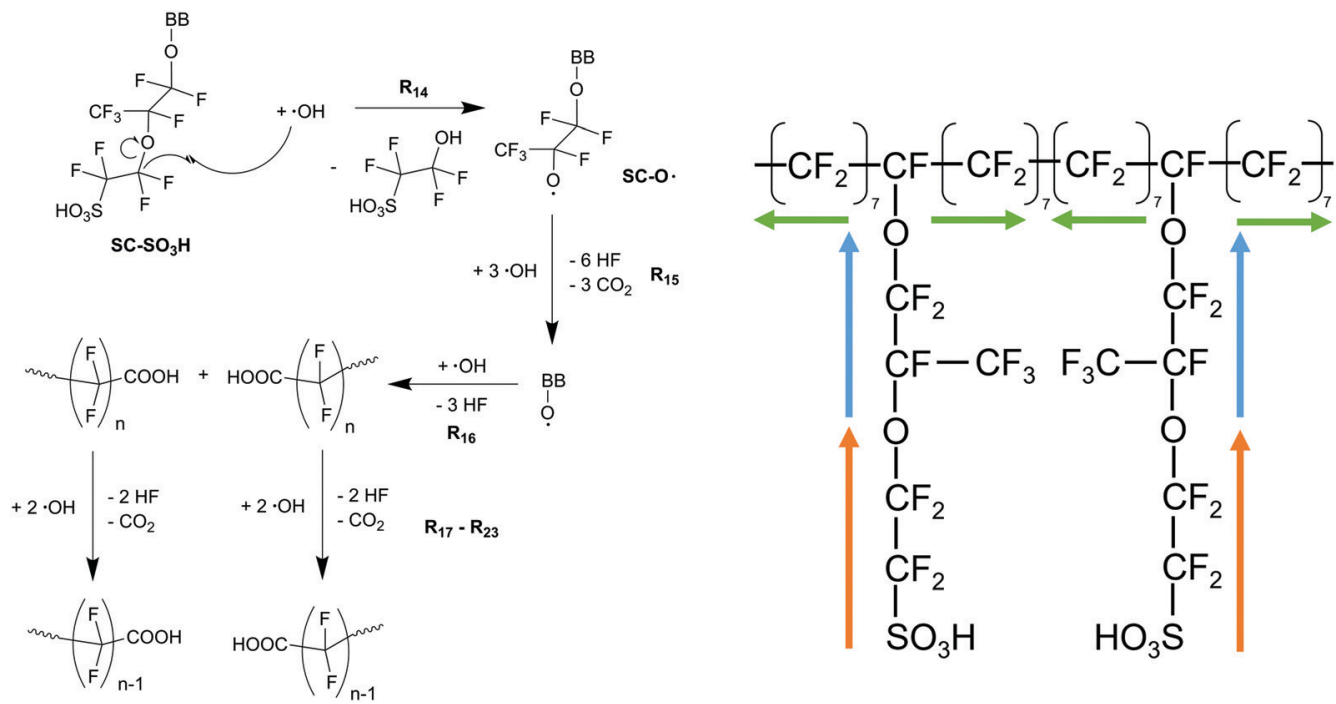

Scheme 6 Left: Side chain degradation mechanism ${ }^{33-35}$ used in the following modelling approach. Right: Upon initiation at the side chain (orange and blue arrows), membrane degradation proceeds in both directions along the backbone equally (indicated by green arrows). 
Table 1 Summary of kinetic data used in this study. For each reaction $\left(R_{1}-R_{23}\right)$, rate constant $k$ at $25^{\circ} \mathrm{C}\left(=298.15 \mathrm{~K}^{\prime}\right.$ in $\mathrm{L} \mathrm{mol}^{-1} \mathrm{~s}^{-1}$, activation energy $E_{\mathrm{a}}$ in $\mathrm{kJ} \mathrm{mol}{ }^{-1}$ and pre-exponential factor $A$ in $\mathrm{L} \mathrm{mol}^{-1} \mathrm{~s}^{-1}$ are given

\begin{tabular}{|c|c|c|c|c|c|}
\hline $\mathrm{R}_{1}$ & $\mathrm{Fe}^{2+}+\mathrm{H}_{2} \mathrm{O}_{2}+\mathrm{H}^{+} \rightarrow \mathrm{Fe}^{3+}+\bullet \mathrm{OH}+\mathrm{H}_{2} \mathrm{O}$ & $r_{1}=k_{1}\left[\mathrm{Fe}^{2+}\right]\left[\mathrm{H}_{2} \mathrm{O}_{2}\right]$ & 66 & $35.4^{15}$ & $1.05 \times 10^{815}$ \\
\hline $\mathrm{R}_{3}$ & $\mathrm{Fe}^{2+}+{ }^{\bullet} \mathrm{OH}+\mathrm{H}^{+} \rightarrow \mathrm{Fe}^{3+}+\mathrm{H}_{2} \mathrm{O}$ & $r_{3}=k_{3}\left[\mathrm{Fe}^{2+}\right]\left[{ }^{\bullet} \mathrm{OH}\right]$ & $3.6 \times 10^{819 a}$ & $9^{19}$ & $1.37 \times 10^{10}$ \\
\hline $\mathrm{R}_{4}$ & $\mathrm{Fe}^{2+}+{ }^{\bullet} \mathrm{OOH}+\mathrm{H}^{+} \rightarrow \mathrm{Fe}^{3+}+\mathrm{H}_{2} \mathrm{O}_{2}$ & $r_{4}=k_{4}\left[\mathrm{Fe}^{2+}\right]\left[{ }^{\bullet} \mathrm{OOH}\right]$ & $1.2 \times 10^{623}$ & $42^{23}$ & $2.74 \times 10^{13}$ \\
\hline $\mathrm{R}_{5}$ & $\mathrm{Fe}^{3+}+{ }^{\bullet} \mathrm{OOH} \rightarrow \mathrm{Fe}^{2+}+\mathrm{H}^{+}+\mathrm{O}_{2}$ & $r_{5}=k_{5}\left[\mathrm{Fe}^{3+}\right]\left[{ }^{\bullet} \mathrm{OOH}\right]$ & $8.1 \times 10^{418}$ & $33^{17,18}$ & $4.9 \times 10^{10}$ \\
\hline $\mathrm{R}_{6}$ & $\mathrm{H}_{2} \mathrm{O}_{2} \rightarrow 2^{\bullet} \mathrm{OH}$ & $r_{6}=k_{6}\left[\mathrm{H}_{2} \mathrm{O}_{2}\right]$ & $6.5 \times 10^{-23}\left[\mathrm{~s}^{-1}\right]$ & $201^{21}$ & $10^{13}\left[\mathrm{~s}^{-1}\right]^{21}$ \\
\hline $\mathrm{R}_{9}$ & $2^{\bullet} \mathrm{OOH} \rightarrow \mathrm{H}_{2} \mathrm{O}_{2}+\mathrm{O}_{2}$ & $r_{9}=k_{9}\left[{ }^{\circ} \mathrm{OOH}\right]^{2}$ & $9.1 \times 10^{524 a}$ & $20.6^{16}$ & $3.70 \times 10^{9}$ \\
\hline $\mathrm{R}_{10}$ & $2^{\bullet} \mathrm{OH} \rightarrow \mathrm{H}_{2} \mathrm{O}_{2}$ & $r_{10}=k_{10}\left[{ }^{\bullet} \mathrm{OH}\right]^{2}$ & $5.3 \times 10^{927 a}$ & $8^{25}$ & $1.33 \times 10^{11}$ \\
\hline $\mathrm{R}_{11}$ & $\bullet \mathrm{OOH}+{ }^{\bullet} \mathrm{OH} \rightarrow \mathrm{H}_{2} \mathrm{O}+\mathrm{O}_{2}$ & $r_{11}=k_{11}\left[{ }^{\bullet} \mathrm{OOH}\right]\left[\bullet^{\bullet} \mathrm{OH}\right]$ & $1.1 \times 10^{1027 a}$ & $14.2^{16}$ & $3.39 \times 10^{12}$ \\
\hline $\mathrm{R}_{12}$ & $\cdot \mathrm{OH}+\mathrm{H}_{2} \rightarrow \mathrm{H}_{2} \mathrm{O}+\cdot{ }^{-}$ & $r_{12}=k_{12}\left[{ }^{\bullet} \mathrm{OH}\right]\left[\mathrm{H}_{2}\right]$ & $3.9 \times 10^{727 a}$ & $19.2^{27}$ & $9.14 \times 10^{10}$ \\
\hline $\mathrm{R}_{13}$ & ${ }^{\bullet} \mathrm{H}+\mathrm{O}_{2} \rightarrow \cdot \mathrm{OOH}$ & $r_{13}=k_{13}\left[{ }^{\bullet} \mathrm{H}\right]\left[\mathrm{O}_{2}\right]$ & $2.2 \times 10^{1027 a}$ & $10.3^{16}$ & $1.37 \times 10^{12}$ \\
\hline $\mathrm{R}_{14}$ & $\mathrm{SC}-\mathrm{SO}_{3} \mathrm{H}+{ }^{\bullet} \mathrm{OH} \rightarrow \mathrm{SC}-\mathrm{O}^{\bullet}+\mathrm{HOCF}_{2} \mathrm{CF}_{2} \mathrm{SO}_{3} \mathrm{H}$ & $r_{14}=k_{14}\left[\mathrm{SC}-\mathrm{SO}_{3} \mathrm{H}\right]\left[{ }^{\bullet} \mathrm{OH}\right]$ & $3.7 \times 10^{620}$ & $70^{c}$ & $6.80 \times 10^{18}$ \\
\hline $\mathrm{R}_{15}$ & $\mathrm{SC}-\mathrm{O}^{\bullet}+3^{\bullet} \mathrm{OH} \rightarrow \mathrm{BB}-\mathrm{O}^{\bullet}+6 \mathrm{HF}+3 \mathrm{CO}_{2}$ & $r_{15}=k_{15}\left[\mathrm{SC}-\mathrm{O}^{\bullet}\right]\left[\left[^{\bullet} \mathrm{OH}\right]\right.$ & $3 \times 10^{733}$ & $70^{c}$ & $5.51 \times 10^{19}$ \\
\hline
\end{tabular}

$(7 \leq n \leq 1)$

$-\left(\mathrm{CF}_{2}\right)_{n-1} \mathrm{COOH}+\mathrm{CO}_{2}+2 \mathrm{HF}$

${ }^{a}$ Rate constants were recalculated for $T=298.15 \mathrm{~K} .{ }^{b}$ Activation energy is estimated between 6 and $10 \mathrm{kcal}^{\mathrm{mol}}{ }^{-1}$. ${ }^{c}$ Average activation energy found in various degradation experiments. ${ }^{31,86 d}$ Upper limit for the attack of ${ }^{\bullet} \mathrm{OH}$ on $\mathrm{CF}_{3} \mathrm{COOH}^{28}$

Although not many experimental activation parameters have been established, the use of DFT-calculated Arrhenius parameters is problematic because due to the subtle interplay of solvent and counter-ion effects they may substantially deviate from their experimental counterparts. ${ }^{84,87}$ The set of coupled chemical reactions shown in Table 1 gives rise to a system of coupled differential equations (displayed in Table 2), which needs to be solved in order to obtain the time traces of all participating chemical species. An overview of parameters (concentrations, temperature, thickness of the membrane)

Table 2 System of coupled differential equations for all relevant species

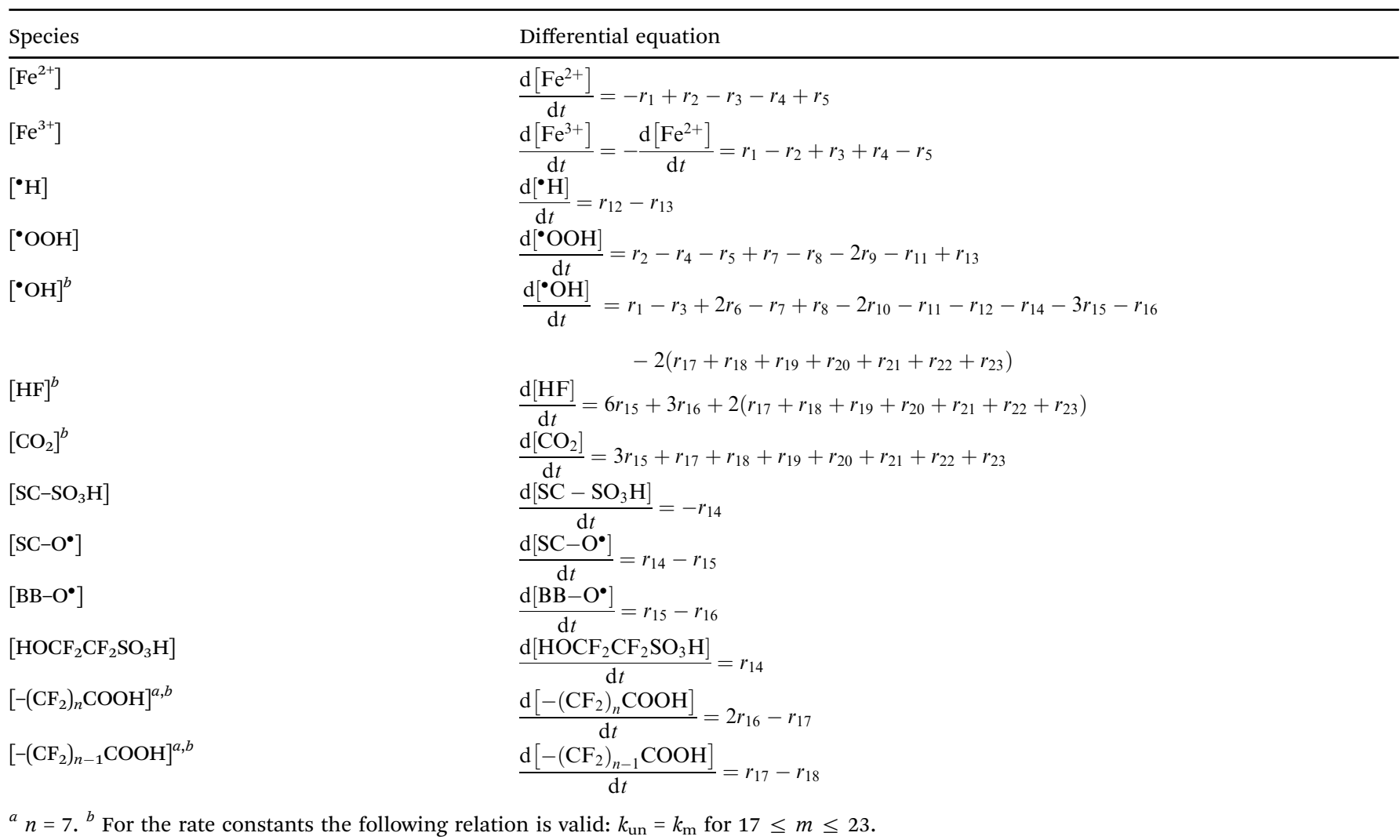


Table 3 Overview of parameters and their typical ranges used in the simulations of in situ conditions

\begin{tabular}{ll}
\hline Parameter & Values \\
\hline$\left[\mathrm{H}_{2} \mathrm{O}_{2}\right]$ & $0.1-10 \mathrm{mM}$ (constant) \\
{$\left[\mathrm{Fe}^{2+}\right]_{0}$} & $1-100 \mathrm{ppm}^{a}$ \\
{$\left[\mathrm{Fe}^{3+}\right]_{0}$} & $1-100 \mathrm{ppm}^{a}$ \\
{$\left[\mathrm{Fe}^{x+}\right]^{x+15}$} & $=\left[\mathrm{Fe}^{2+}\right]_{0}+\left[\mathrm{Fe}^{3+}\right]_{0}$ (constant) \\
{$\left[\mathrm{SC}-\mathrm{SO}_{3} \mathrm{H}\right]_{0}$} & $1.81 \mathrm{M}^{34 b}$ \\
{$\left[\mathrm{H}_{2}\right]$} & $10 \mathrm{mM}$ (constant) $)^{31}$ \\
{$\left[\mathrm{O}_{2}\right]$} & $7.5 \mathrm{mM}$ (constant) \\
$T$ & $333.15-368.15 \mathrm{~K}$ \\
$\delta_{\text {membrane }}$ & $25-50 \mu \mathrm{m}$ \\
${ }^{a}{ }_{1}$ ppm Fe corresponds to $1.79 \times 10^{-5} \mathrm{M} .{ }^{b}\left[\mathrm{SC}-\mathrm{SO}{ }_{3} \mathrm{H}\right]_{0}$ is calculated as \\
the ratio between dry membrane density $\rho_{\text {membrane }}$ and BOL equivalent \\
weight EW ${ }_{0}{ }^{34}$
\end{tabular}

which are used in the model and can be adjusted freely is presented in Table 3.

\section{Methods}

The system of coupled differential equations was solved by using a combination of the freely available kinetic simulation software COPASI ${ }^{85}$ (http://copasi.org) and an automatisation routine (COPASI driver, developed by us) implemented in the programming language Perl. All inputs are provided in a plain text file (obeying a certain syntax) and are then interpreted by the routine which generates the inputs for the commandline version of COPASI (version 4.24 (Build 197)). The results are processed by copd to yield output text files and graphical representations (time traces and rate plots; generated via gnuplot (version 5.2 patchlevel 4)), which allow a first fast assessment of the received data. Examples of an input file and output files of the routine are provided in the ESI. $\dagger$ Origin Pro 8 was used to fit the calculated data shown in Fig. 13. Simulations are generally fast $(4.4 \mathrm{~s}$ for $100 \mathrm{~h}$ real-time simulation of a chemical reactor on a Windows 10 64-bit PC equipped with an Intel ${ }^{\mathbb{R}}$ Core i5-3210M processor and 8GB RAM). The kinetic framework can also be used with Linux. A web interface of the routine can be freely accessed under http://ptc-pc-139. tugraz.at/cgi-bin/Membrane_Degradation/.
To inspect if the results generated by the COPASI driver are of general nature, we have also implemented the equations in Mathematica (Version 11). A comparison of the results obtained from both the copd routine and the Mathematica implementation is shown in the ESI. $\dagger$ The used Mathematica code is available in the $\mathrm{ESI}^{\dagger}$ and free to use.

\section{Results and discussion}

To establish a holistic chemical degradation modelling framework based on the equations presented in Table 1, several aspects - the interplay of iron species and radicals, their influence on the ionomer degradation and the dependence of fluoride emission on the temperature, $\left[\mathrm{Fe}^{x+}\right]$ and $\left[\mathrm{H}_{2} \mathrm{O}_{2}\right]-$ are highlighted in this section. Furthermore, the model allows analysing the entire cause and effect chain of chemical degradation phenomena ranging from basic radical formation reactions to the (measurable) manifestations of membrane degradation (fluoride emissions, loss of ionomer moieties and loss of ion exchange capacity).

\section{Dynamic equilibrium between ferrous and ferric ion}

Transition metals like $\mathrm{Cu}^{+}$or $\mathrm{Co}^{2+}$ are also capable of converting $\mathrm{H}_{2} \mathrm{O}_{2}$ to ROS. The modular setup of the framework allows that reactions for additional metal contaminants can be added to the system easily. Iron ions, however, are known as contaminants in fuel cell membranes. ${ }^{57,60-62}$ We consider iron as a paradigm of all "Fenton-active" metal salts, whose exact distribution and concentrations remain unresolved. Furthermore, the reactions of $\mathrm{Fe}^{2+}$ and $\mathrm{Fe}^{3+}$ with $\mathrm{H}_{2} \mathrm{O}_{2}$ and radical species are very well studied (see $R_{1}-R_{5}$ ). ${ }^{15,17-19,22,23,58,59,88,89}$ All 5 reactions can be characterised as redox reactions and constitute a recycling system for the oxidation state of the iron. As a dynamic equilibrium between the two main oxidation states of iron (+II and +III) is established, it should not be relevant in which oxidation state the iron ions are present at the initial state of the simulation.

This hypothesis was tested by comparing the time traces for the iron and radical species for two test cases - in the first one
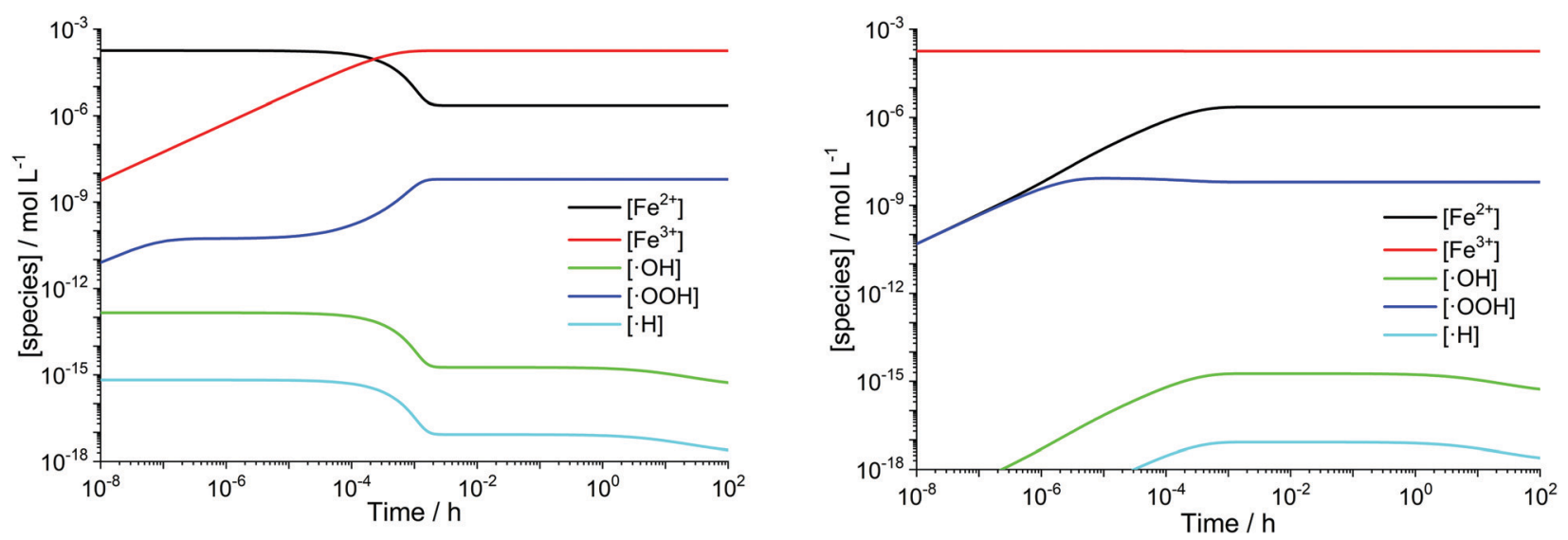

Fig. $3 \log$-log plots of $\left[\mathrm{Fe}^{x+}\right]$ and radical concentrations as a function of time for $T=363.15 \mathrm{~K}$. Left: $\left[\mathrm{H}_{2} \mathrm{O}_{2}\right]=1 \mathrm{mM},\left[\mathrm{Fe} e^{2+}\right]_{0}=10 \mathrm{ppm}$. Right: $\left[\mathrm{H}_{2} \mathrm{O}_{2}\right]=$ $1 \mathrm{mM},\left[\mathrm{Fe}^{3+}\right]_{0}=10 \mathrm{ppm}$. 
$10 \mathrm{ppm}$ Fe is present in +II state at $t=0$ and in the second one the same amount of $\mathrm{Fe}$ is in the + III state at $t=0$. The results are presented in Fig. 3 and indicate that in the first few seconds of the simulation a constant ratio between both iron species is formed. From this moment on 99\% of the iron species are in the +III state and lead to matching concentration curves for all depicted chemical species for both cases. The graphical representation of the time traces for the chemical reactor with $\left[\mathrm{Fe}^{2+}\right]=10$ ppm and $\left[\mathrm{Fe}^{3+}\right]=0$ ppm (left side of Fig. 3) reveals a remarkable correlation between the concentrations of the ferrous ion and the radicals ${ }^{\bullet} \mathrm{OH}$ and ${ }^{\bullet} \mathrm{H}$. The time traces representing these radicals are strongly influenced by the transient concentration of ferrous ions. $\left[{ }^{\bullet} \mathrm{OH}\right]$ and $\left[{ }^{\bullet} \mathrm{H}\right]$ drop as soon as major parts of the ferrous ion are oxidised. This observation is reasonable, as the Fenton reaction $\left(\mathrm{R}_{1}\right)$ is one of the prominent sources of $\bullet^{\bullet} \mathrm{OH}$. The concentration of $\bullet^{\bullet} \mathrm{H}$ follows the time trace of ${ }^{\bullet} \mathrm{OH}$, as their sole source is the reaction between $\mathrm{H}_{2}$ and ${ }^{\bullet} \mathrm{OH}\left(\mathrm{R}_{12}\right)$. Parallel to the oxidation of iron, the concentration of ${ }^{\bullet} \mathrm{OOH}$ increases (with a short stagnation) until reaching a steady-state concentration after a few seconds.

A similar behaviour is observable for the inverse case - all iron ions are in + III at $t=0-$ shown on the right side of Fig. 3 . The reduction of ferric ions to ferrous ions is only carried out via the reaction with $\mathrm{H}_{2} \mathrm{O}_{2}\left(\mathrm{R}_{2}\right)$ and subsequently with newly formed ${ }^{\bullet} \mathrm{OOH}\left(\mathrm{R}_{5}\right)$. Up to $10^{-6} \mathrm{~s}$, the concentrations of $\mathrm{Fe}^{2+}$ and ${ }^{\bullet} \mathrm{OOH}$, which are both products of $\mathrm{R}_{2}$, are the same and afterwards, the participation of the species in other chemical reactions leads to a bifurcation of the curves. The concentration of $\mathrm{Fe}^{3+}$ is only weakly influenced, as just about $1 \%$ of the ferric ions are reduced to ferrous ions. This finding is in good agreement with the results from the quasi-steady-state approach by Gubler et al., ${ }^{31}$ who found that in the steadystate $>99 \%$ of the iron ions are $\mathrm{Fe}^{3+}$.

The obtained range of the radical concentrations for the time between $10^{-3} \mathrm{~h}$ and $100 \mathrm{~h}$ are in accordance with the results by Gubler et al., ${ }^{31}$ who calculated $\left[{ }^{\bullet} \mathrm{OOH}\right] \approx 10^{-10} \mathrm{M}$, $\left[{ }^{\bullet} \mathrm{OH}\right] \approx 10^{-16} \mathrm{M}$ and $\left[{ }^{\bullet} \mathrm{H}\right] \approx 10^{-19} \mathrm{M}$. Discrepancies might be explained by the fact that the model presented here does not rely on a steady-state approach and additionally, the temperature dependence of the chemical reactions is included.

\section{Time evolution of membrane degradation}

The time-scale at which a steady-state of the iron and radical species (except for ${ }^{\bullet} \mathrm{OH}$ and ${ }^{\bullet} \mathrm{H}$ ) is established is clearly separated from that of the evolution of the membrane degradation products. As shown in Fig. 3 iron and radical species reach their final concentrations after a few seconds (and then do not depend on differences in the initial concentrations of $\mathrm{Fe}^{2+}$ and $\mathrm{Fe}^{3+}$ anymore). The evolution of the ionomer moieties and degradation products ( $\mathrm{HF}$ and $\mathrm{CO}_{2}$ ) happens on a much longer time-scale as shown in Fig. 4. The radical ether cleavage at the side chain (first step in the degradation mechanism) leads to a decrease in sulfonic acid head group concentration (see Scheme 6). Immediately after the start of degradation the product of the radical ether cleavage $\mathrm{SC}-\mathrm{O}^{\bullet}$ is built up and, with a certain delay, also $\mathrm{BB}-\mathrm{O}^{\bullet}$ and the carboxylic acid

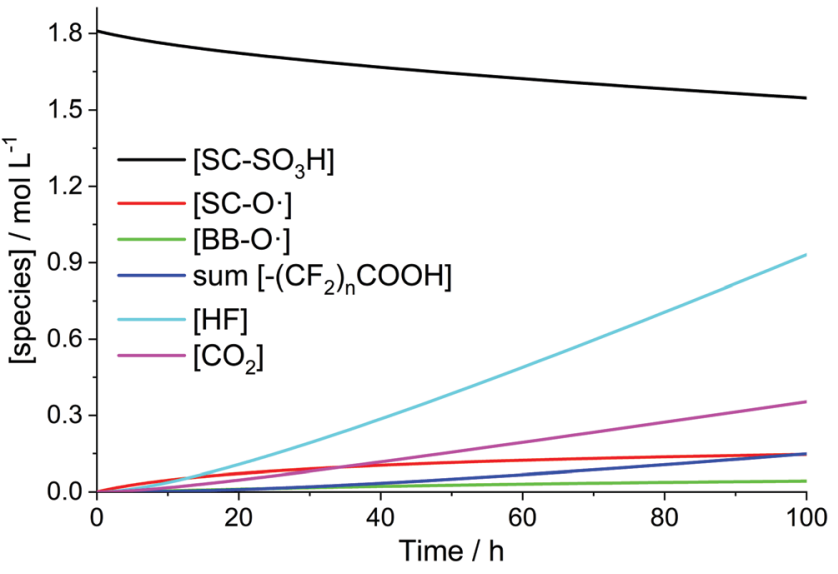

Fig. 4 Time traces of PFSA ionomer functional groups and degradation products for $\left[\mathrm{H}_{2} \mathrm{O}_{2}\right]=1 \mathrm{mM},\left[\mathrm{Fe}^{2+}\right]_{0}=10 \mathrm{ppm}$ and $T=363.15 \mathrm{~K}$.

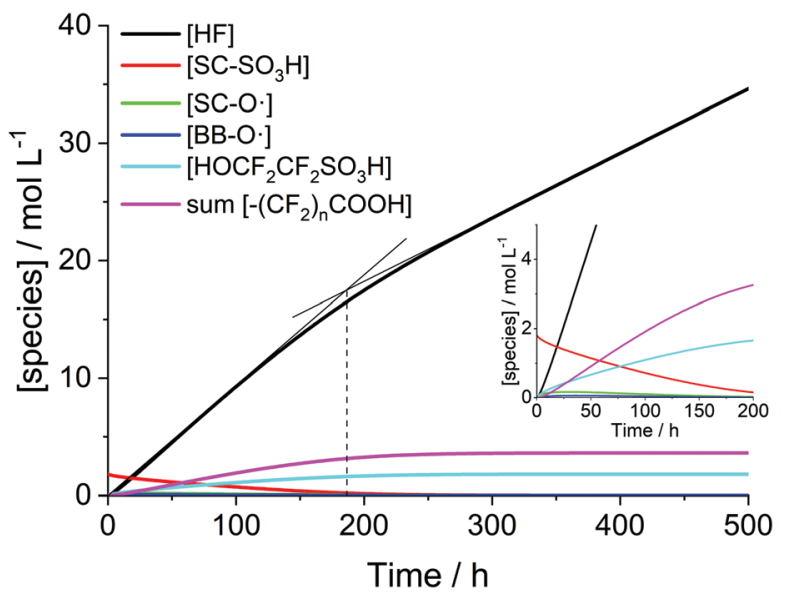

Fig. 5 Time traces of PFSA ionomer functional groups and degradation products for $\left[\mathrm{H}_{2} \mathrm{O}_{2}\right]=5 \mathrm{mM},\left[\mathrm{Fe}^{2+}\right]_{0}=10 \mathrm{ppm}$ and $T=368.15 \mathrm{~K}$. The bend in the concentration trace of HF (change in the degradation mechanism) is indicated by two intersecting lines and a dashed line.

terminated main chain fragments are generated. The occurrence of the intermediates also correlates with the drop of concentration of ${ }^{\bullet} \mathrm{OH}$ observed after a few hours (see Fig. 3), as the degradation of these intermediates $\left(\mathrm{R}_{15}-\mathrm{R}_{23}\right)$ consumes additional ${ }^{\bullet} \mathrm{OH}$. Despite the favourable kinetics for the attack of the membrane by ${ }^{\bullet} \mathrm{OH}$ with rate constants $>10^{6} \mathrm{~L} \mathrm{~mol}^{-1} \mathrm{~s}^{-1}$ membrane degradation is greatly decelerated by the low steadystate concentration of ${ }^{\bullet} \mathrm{OH}$ (see Fig. 3).

When plotting the concentration traces for harsher conditions $\left(\left[\mathrm{H}_{2} \mathrm{O}_{2}\right]=5 \mathrm{mM},\left[\mathrm{Fe}^{2+}\right]_{0}=10\right.$ ppm and $T=368.15 \mathrm{~K}$; Fig. 5$)$, the curve for HF levels off in the area around $200 \mathrm{~h}$. Up to this point, the fast degradation reactions of the side chain $\left(\mathrm{R}_{15}\right.$ and $\mathrm{R}_{16}$ ) mainly contribute to the fluoride emission. As soon as most of the side chain is consumed (at around $200 \mathrm{~h}$ ), the emitted fluoride stems exclusively from the unzipping of the main chain $\left(\mathrm{R}_{17-23}\right)$, which is characterized by a smaller rate constant and becomes rate-determining in terms of fluoride emission. 


\section{Trends in fluoride emission rates}

Among the most important parameters to assess the state of health of an ionomer membrane is the fluoride emission rate, which is usually determined in effluent water by using fluoride sensitive electrodes or high performance liquid chromatography. ${ }^{5}$ The FER is inversely proportional to the life-time of the membrane as it is directly linked to its loss of mass, which will be highlighted further below in the text.

Besides time traces for the concentrations of the chemical species, the copd routine outputs FER data derived from the concentration of HF. The FER values (averaged over $100 \mathrm{~h}$ ) were calculated for different $\left[\mathrm{Fe}^{2+}\right]_{0}$ and $\left[\mathrm{H}_{2} \mathrm{O}_{2}\right]$ values and $T=70{ }^{\circ} \mathrm{C}$ (see Fig. 6). For low $\left[\mathrm{Fe}^{2+}\right]_{0}$ and $\left[\mathrm{H}_{2} \mathrm{O}_{2}\right]$, small FER values are obtained, as expected. The FER shows a strong dependency on both $\left[\mathrm{Fe}^{2+}\right]_{0}$ and $\left[\mathrm{H}_{2} \mathrm{O}_{2}\right]$ which is indicated by the orange and black lines. Hence, a low concentration of both iron contaminants and detrimental hydrogen peroxide is necessary to protect the chemical integrity of the membrane.

Another factor which greatly influences the fluoride emission is the temperature within the fuel cell membrane (see Fig. 7). By increasing the temperature by only $10 \mathrm{~K}$ (e.g. going from $333.15 \mathrm{~K}$ to $343.15 \mathrm{~K}$ ) while keeping $\left[\mathrm{Fe}^{2+}\right]$ constant, a gain in the fluoride emission rate of up to one order of magnitude results. The increase in fluoride emission is less pronounced for higher initial concentrations of $\mathrm{Fe}^{2+}$.

In addition to the FER, the ion exchange capacity of the ionomer is also an indicator of the chemical integrity of the membrane. When the sulfonic acid moieties are eliminated due to degradation phenomena, the ion exchange capacity (IEC) decreases. To investigate the correlation with the fluoride emission rate, we calculated the IEC (at BOL) as the ratio of the amount of sulfonic acid groups in mmol $\left(n_{0}\right)$ and the dry mass of the ionomer in $\mathrm{g}\left(m_{\mathrm{dry}, 0}\right)$ in the following equation: ${ }^{33}$

$$
\mathrm{IEC}_{0}=\frac{n_{0}\left(\mathrm{SO}_{3} \mathrm{H}\right)}{m_{\mathrm{dry}, 0}}
$$

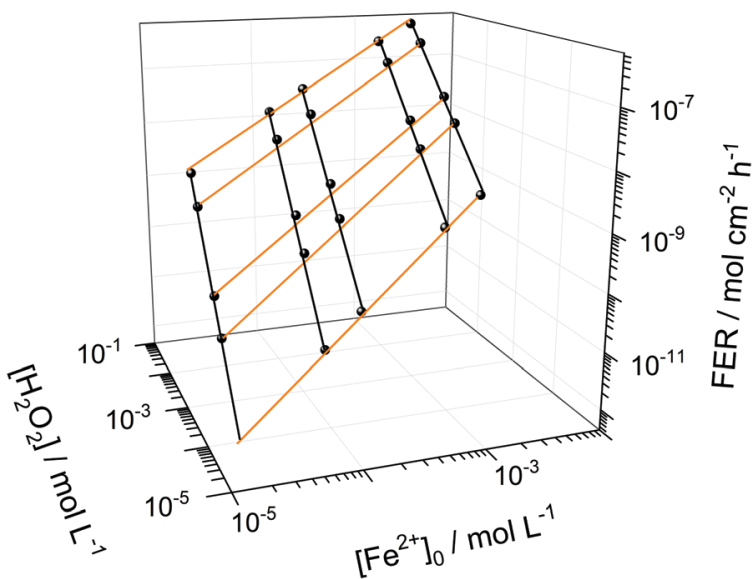

Fig. 6 Logarithmic depiction of the fluoride emission rate (averaged over $100 \mathrm{~h}$ ) as a function of hydrogen peroxide concentration and initial ferrous ion concentration for $T=343.15 \mathrm{~K}$ and $\delta_{\text {membrane }}=50 \mu \mathrm{m}$. The black lines indicate constant initial ferrous ion concentration and the orange lines indicate constant hydrogen peroxide concentration.

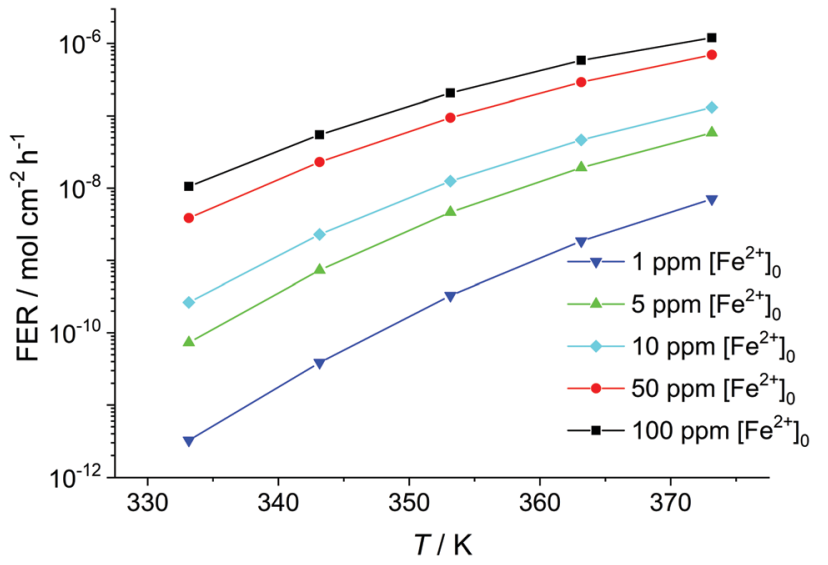

Fig. 7 Fluoride emission rate (averaged over $100 \mathrm{~h}$ ) given in mol cm $\mathrm{cm}^{-2} \mathrm{~h}^{-1}$ calculated as a function of temperature in $\mathrm{K}$ for $\left[\mathrm{H}_{2} \mathrm{O}_{2}\right]=1 \mathrm{mM}$ and $\delta_{\text {membrane }}=50 \mu \mathrm{m}$.

When the ionomer is subjected to chemical degradation, the number of sulfonic acid group decreases, and the mass of the ionomer is diminished by the loss of $\mathrm{CF}_{2}$ groups $\left(m_{\mathrm{C}}+m_{\mathrm{F}}\right)$ and the fragment $\mathrm{HOCF}_{2} \mathrm{CF}_{2} \mathrm{SO}_{3} \mathrm{H}$ ( $\left.m_{\text {fragment }}\right)$ formed in $\mathrm{R}_{14}$ :

$$
\mathrm{IEC}=\frac{n\left(\mathrm{SO}_{3} \mathrm{H}\right)}{m_{\mathrm{dry}, 0}-m_{\mathrm{C}}-m_{\mathrm{F}}-m_{\mathrm{fragment}}}
$$

For the calculations of the IEC after a simulated degradation test, a membrane area of $25 \mathrm{~cm}^{2}$, a constant membrane thickness of $50 \mu \mathrm{m}$ and hence a volume of $1.25 \times 10^{-4} \mathrm{~L}$ are assumed. The density of Nafion is $1.98 \mathrm{~g} \mathrm{~cm}^{-3} .^{90}$ The FER values (averaged over $100 \mathrm{~h}$ ) are plotted as a function of IEC values obtained at the end of simulation $(100 \mathrm{~h})$ in Fig. 8. With increasing temperature and iron contaminant concentration the FER is increased and approaches a value of about $10^{-6} \mathrm{~mol} \mathrm{~cm}^{-2} \mathrm{~h}^{-1}$. At the same time, the IEC drops until reaching $0 \mathrm{mmol} \mathrm{g}^{-1}$, the point at which all side chains are degraded (left side of Fig. 8). In the other direction, it is evident that a value of $0.91 \mathrm{mmol} \mathrm{g}^{-1}$ is approached, which corresponds to the $\mathrm{IEC}_{0}$ value of a pristine membrane, ${ }^{13}$

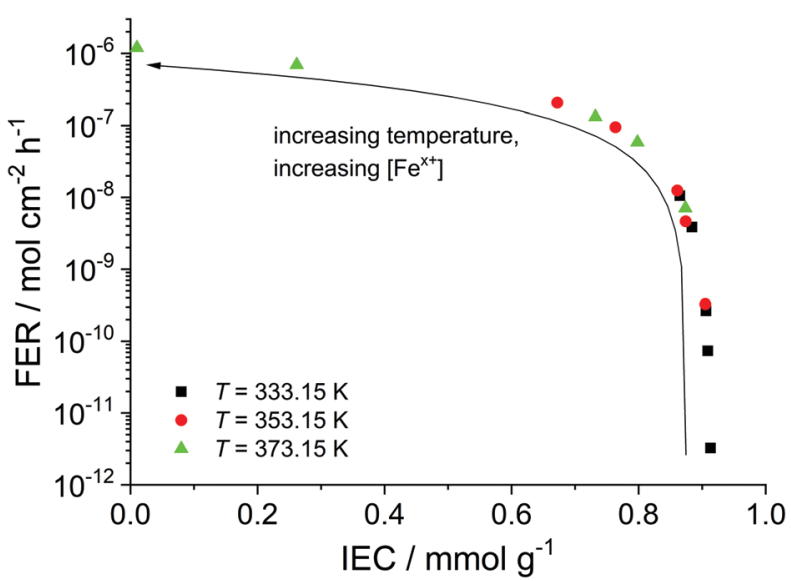

Fig. 8 Fluoride emission rate (averaged over $100 \mathrm{~h}$ ) is plotted as a function of the ion exchange capacity (at $t=100 \mathrm{~h}$ ). The arrow indicates increasing temperature and iron concentration. 
as virtually no side chains are consumed at lower temperatures (333.15 K) and lower iron concentrations ( $1 \mathrm{ppm})$. The IEC is only affected critically, when the FER exceeds a certain threshold (about $\left.10^{-7} \mathrm{~mol} \mathrm{~cm}{ }^{-2} \mathrm{~h}^{-1}\right)$.

\section{Influence of iron input and leaching on membrane degradation}

For the results presented so far, the total iron concentration $\left[\mathrm{Fe}^{x+}\right]$ was kept constant over the whole course of the simulation. The implications of changing the total iron concentration due to input of additional iron (e.g. demetallation of the $\mathrm{Fe}-\mathrm{N}-\mathrm{C}$ catalyst; $^{38,39}$ originating from stainless steel end plates ${ }^{57,60}$ ) or loss of iron are demonstrated in the following paragraphs.

For the analysis, it was assumed that all iron, which is added or lost, is in the oxidation state + II. This assumption is justified, as simulations presented above show that the dynamic equilibrium between both oxidation states of iron is established within seconds. The rate constant, which describes the input or loss (output) of iron $\left(k_{\mathrm{I} / \mathrm{O}}\right)$, was calculated so that the final total iron concentrations are reached at the end of the simulation (linear increase and decrease). This means that $k_{\mathrm{I} / \mathrm{O}}=$ $\pm 4.972 \times 10^{-10} \mathrm{~mol} \mathrm{~L}^{-1} \mathrm{~s}^{-1}$ (positive for $10 \rightarrow 20 \mathrm{ppm}$ and negative for $10 \rightarrow 0 \mathrm{ppm}$ ) is obtained. The differential equation for $\left[\mathrm{Fe}^{2+}\right]$ can be written as

$$
\frac{\mathrm{d}\left[\mathrm{Fe}^{2+}\right]}{\mathrm{d} t}=-r_{1}+r_{2}-r_{3}-r_{4}+r_{5}+k_{\mathrm{I} / \mathrm{O}}
$$

The results, which are depicted in Fig. 9, reveal that the input or leaching of $\mathrm{Fe}^{x+}$ has a great influence on the kinetics of the degradation, as expected. The green curves show the cases when $\left[\mathrm{Fe}^{x+}\right]$ is decreased from 10 to $0 \mathrm{ppm}$. At the end of the simulation the slope of the green curves tends to 0 , as the system becomes almost depleted of $\left[\mathrm{Fe}^{x+}\right]$. For the increase of $\left[\mathrm{Fe}^{x+}\right]$ from 10 to $20 \mathrm{ppm}$ (blue curves) the slope of the curves grows until the blue curves are parallel to the black curves $\left(20 \mathrm{ppm}\left[\mathrm{Fe}^{x+}\right]\right)$. To avoid the acceleration of chemical degradation, it is highly important to optimize the constituents of the fuel cell (e.g. the end plates or the $\mathrm{Fe}-\mathrm{N}-\mathrm{C}$ catalysts) in a way that the input of additional iron species is minimized.

\section{Comparison with experimental data}

The simulation results presented so far were derived from a model that assumes a $0 \mathrm{D}$ chemical reactor. In reality, membrane degradation is a complex interplay of chemical and physical (thermal and mechanical) processes. To demonstrate that our model, despite its limitations, produces reasonable results, we will compare simulation results with a number of experimental data sets in the following paragraphs.

Wong and Kjeang ${ }^{33}$ validated their membrane degradation model by comparing it to the results from a cyclic open circuit voltage accelerated stress test (COCV AST). ${ }^{19} \mathrm{~F}$ NMR spectroscopy was employed to monitor the loss of functional groups $\left(-\mathrm{SO}_{3} \mathrm{H}, \mathrm{CF}(\mathrm{s}), \mathrm{CF}(\mathrm{m})\right.$; for assignment see Fig. 2) during the AST. The measured concentrations of these groups after 0,20 , 50 and $70 \mathrm{~h}$ are shown in Fig. 10. Based on the experimental parameters $\left(\left[\mathrm{Fe}^{x+}\right]=6 \mathrm{ppm}\right)$ the results were reproduced by the

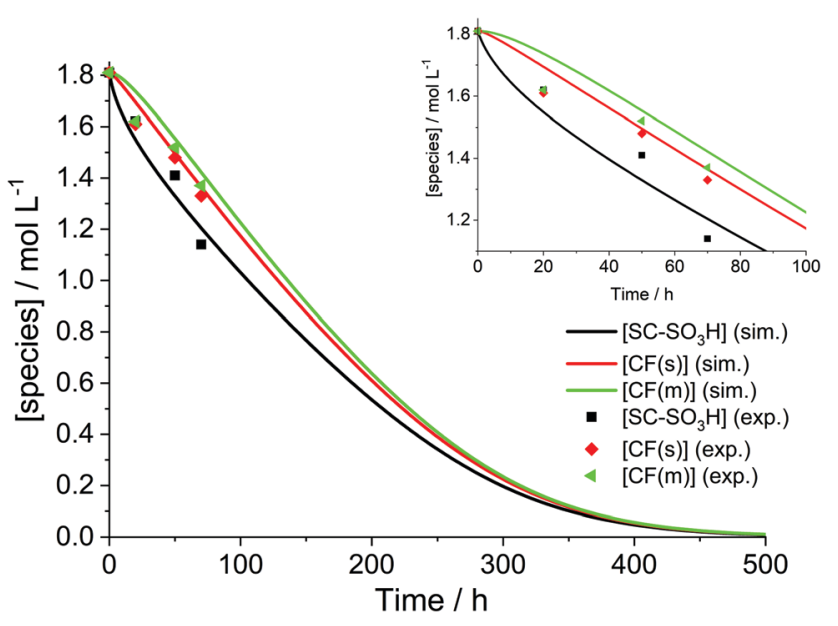

Fig. 10 Temporal evolution of the ionomer functional moieties. The inset shows the curves and the experimental data during the first $100 \mathrm{~h}$. Simulation (sim.) parameters: $T=368.15 \mathrm{~K},\left[\mathrm{H}_{2} \mathrm{O}_{2}\right]=5.2 \mathrm{mM},\left[\mathrm{Fe}^{2+}\right]_{0}=$ $6 \mathrm{ppm}$. Experimental (exp.) results were taken from an AST ([Fe $\left.\left.{ }^{x+}\right]=6 \mathrm{ppm}\right)$ by Wong and Kjeang. ${ }^{33}$
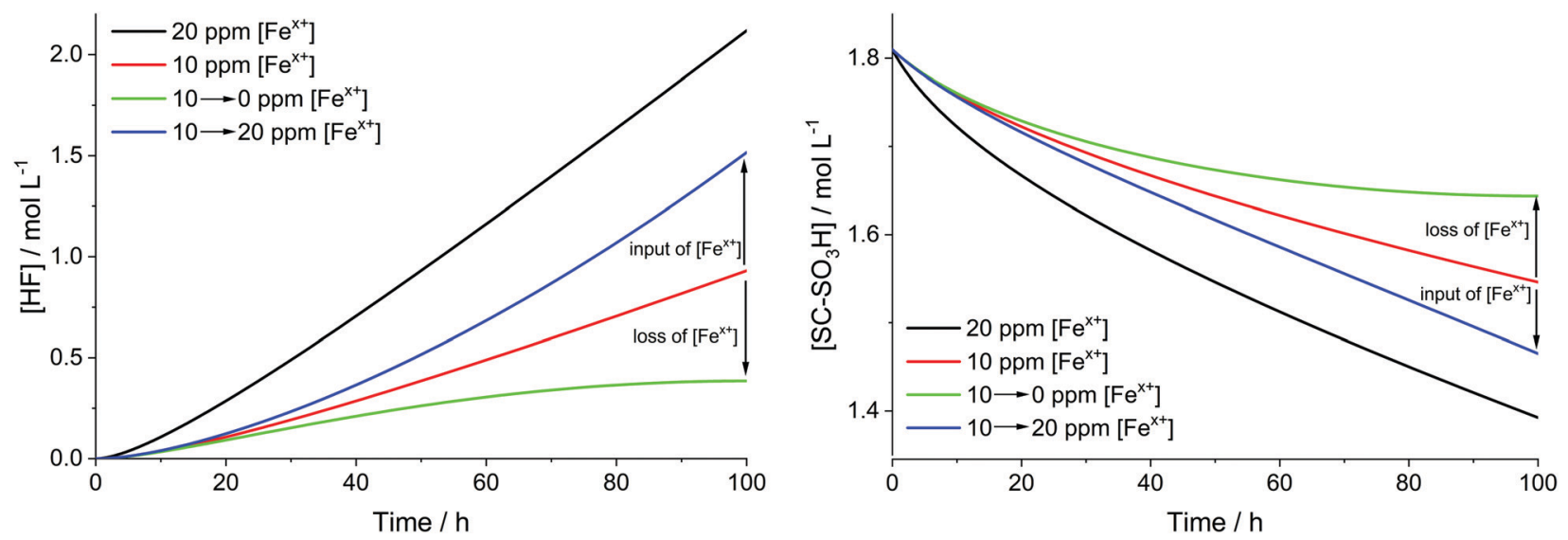

Fig. 9 Influence of total iron concentration $\left[\mathrm{Fe}^{\mathrm{x+}}\right]$ on the time traces of $\mathrm{HF}$ (left) and $\mathrm{SC}-\mathrm{SO}_{3} \mathrm{H}$ (right) for $T=363.15 \mathrm{~K}$ and $\left[\mathrm{H}_{2} \mathrm{O}_{2}\right]=1 \mathrm{mM}$. The green and blue curves indicate cases where additional iron is added to the system (10 $\rightarrow 20 \mathrm{ppm}$, blue) and removed from the system (10 $\rightarrow 0 \mathrm{ppm}$, green). 
Table 4 Error estimations based on experimental data $\left({ }^{19} \mathrm{~F} \mathrm{NMR}\right)^{12,13}$ compared to the deviations between experimental and simulated values (for 20,50 and $70 \mathrm{~h}$ ) shown in Fig. 10

\begin{tabular}{|c|c|c|c|c|c|}
\hline PFSA moiety & \multicolumn{3}{|c|}{$\underline{\text { Relative deviations between experimental }\left(c_{\exp }\right) \text { and simulated concentrations }\left(c_{\text {sim }}\right)^{a}}$} & \multicolumn{2}{|c|}{$\underline{\text { Experimental errors }}^{b}$} \\
\hline$-\mathrm{CF}_{2} \mathrm{SO}_{3} \mathrm{H}\left(\stackrel{\wedge}{=} \mathrm{SC}-\mathrm{SO}_{3} \mathrm{H}\right)$ & $5 \%$ & $6 \%$ & $6 \%$ & $\pm 2 \%$ & $\pm 3 \%$ \\
\hline $\mathrm{CF}(\mathrm{m})$ & $8 \%$ & $3 \%$ & $4 \%$ & $\pm 8 \%$ & $\pm 10 \%$ \\
\hline
\end{tabular}

simulation. The concentrations of the tertiary carbon moieties in Fig. 10 were calculated using the following relations: ${ }^{33}$

$$
\begin{gathered}
{[\mathrm{CF}(\mathrm{s})]=\left[\mathrm{SC}-\mathrm{SO}_{3} \mathrm{H}\right]+\left[\mathrm{SC}-\mathrm{O}^{\bullet}\right]} \\
{[\mathrm{CF}(\mathrm{m})]=\left[\mathrm{SC}-\mathrm{SO}_{3} \mathrm{H}\right]+\left[\mathrm{SC}-\mathrm{O}^{\bullet}\right]+\left[\mathrm{BB}-\mathrm{O}^{\bullet}\right]}
\end{gathered}
$$

Since $\left[\mathrm{H}_{2} \mathrm{O}_{2}\right]$ and the exact temperature at which the test was run were not stated ${ }^{33,91}$ (OCV phase under high temperature/ low $\mathrm{RH}$ (relative humidity) conditions as described by Lim et $a l .{ }^{91}$ ), these parameters were adjusted in the simulation to give the best agreement between the experimental data and the simulation. $\left[\mathrm{H}_{2} \mathrm{O}_{2}\right]$ was set to $5.2 \mathrm{mM}$ and the temperature to $368.15 \mathrm{~K}$ to yield the time traces in Fig. 10. The temperature $\left(95{ }^{\circ} \mathrm{C}\right)$ is reasonable, as compatible temperatures are employed in fuel cell tests to accelerate degradation. ${ }^{37,92}$ The values of $\left[\mathrm{H}_{2} \mathrm{O}_{2}\right]$ used in the simulations will be discussed below. Under these conditions, a complete consumption of ionomer moieties ( $\mathrm{SC}-\mathrm{SO}_{3} \mathrm{H}, \mathrm{CF}(\mathrm{s})$ and $\mathrm{CF}(\mathrm{m})$ ) is accomplished within approx. 500 hours. From this moment on only - $\mathrm{COOH}$ terminated main chain fragments are present in the chemical reactor.

As no error bars were presented with the experimental data ${ }^{33}$ used in Fig. 10, errors were estimated based on similar ${ }^{19}$ F NMR data. $^{12,13}$ The results, which are outlined in Table 4 , indicate that the relative deviations for both $\mathrm{CF}(\mathrm{s})$ and $\mathrm{CF}(\mathrm{m})$ are below or the same as the lowest experimental errors. For $\mathrm{SC}-\mathrm{SO}_{3} \mathrm{H}$ the experimental errors are about half the size of the relative deviations between experimental and simulated data in Fig. 10. These findings might also provide an explanation for the similarity of the concentration values for all three monitored groups at $20 \mathrm{~h}$ in Fig. 10. Upon consideration of the experimental errors shown in Table 4 a similar trend in concentration (as for 50 and $70 \mathrm{~h}$ ) is expected.

Not only the loss of ionomer moieties during in situ tests but also the temporal evolution of the FER during such experiments can be simulated. The red dots in Fig. 11 show the experimental FER values obtained in a $10 \mathrm{~h}$ long OCV hold experiment by Singh et al. ${ }^{35}$ The data could be well reproduced (black line) by the kinetic framework $\left(\left[\mathrm{H}_{2} \mathrm{O}_{2}\right]=4 \mathrm{mM},\left[\mathrm{Fe}^{2+}\right]_{0}=\right.$ $\left.10 \mathrm{ppm}, \delta_{\text {membrane }}=50 \mu \mathrm{m}\right)$. Due to the lack of diffusion in the oD chemical reactor model a differentiation between fluoride emission on the cathode and anode side is not possible. Therefore, the sum of the experimental FER values, which were higher for the cathode side, had to be used for comparison.

Recently, Futter et $a l .{ }^{36}$ obtained FER values in the range of $10^{-7}$ to $6 \times 10^{-7} \mathrm{~mol} \mathrm{~cm}{ }^{-2} \mathrm{~h}^{-1}$ depending on the conditions of

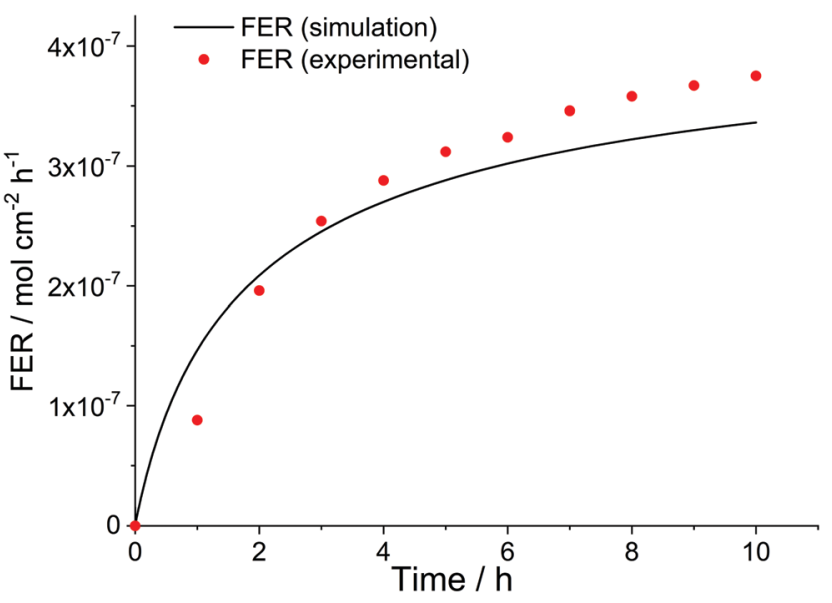

Fig. 11 Time evolution of fluoride emission rate during an OCV hold test. Simulation parameters: $T=368.15 \mathrm{~K},\left[\mathrm{H}_{2} \mathrm{O}_{2}\right]=4 \mathrm{mM},\left[\mathrm{Fe}^{2+}\right]_{0}=10 \mathrm{ppm}$; $\delta_{\text {membrane }}=50 \mu \mathrm{m}$. Experimental results (sum of fluoride emission rate for both anode and cathode side) were taken from an OCV hold test ( $T=$ $368.15 \mathrm{~K})$ by Singh et al. ${ }^{35}$

the performed ASTs $\left(p_{\text {anode }}=1.5-2.5 \mathrm{bar}, p_{\text {cathode }}=1.5-2.3 \mathrm{bar}\right.$, $\mathrm{RH}=30-75 \%)$. To compare the experimental results with the model, the authors multiplied the experimentally obtained FER values by a factor of 20.8 to account for non-detectable fluorine (in the form of membrane fragments). Thus, the FER values for detectable fluorine were found to be between $5 \times 10^{-9}$ and $3 \times 10^{-8} \mathrm{~mol} \mathrm{~cm}{ }^{-2} \mathrm{~h}^{-1} \cdot{ }^{36}$ As our model only calculates the FER based on detectable fluorine, the modelling result will be compared with these values. When taking the conditions from the stress test and the $\operatorname{model}^{36}\left(\left[\mathrm{Fe}^{x+}\right]=2.5 \mathrm{ppm}\right.$; $\left[\mathrm{Fe}^{2+}\right]_{0} /\left[\mathrm{Fe}^{3+}\right]_{0}=1 ; T=368.15 \mathrm{~K}$, Nafion ${ }^{\circledR}$ XL membrane $\left(\delta_{\text {membrane }}=25 \mu \mathrm{m}\right)$ with a $8.33 \mu \mathrm{m}$ thick reinforcement layer) and setting $\left[\mathrm{H}_{2} \mathrm{O}_{2}\right]$ from 0.5 to $3 \mathrm{mM}$, FER values ranging from $3 \times 10^{-9}$ to $3 \times 10^{-8} \mathrm{~mol} \mathrm{~cm}{ }^{-2} \mathrm{~h}^{-1}$ (averaged over $100 \mathrm{~h}$ ) were obtained from the simulation. In addition to the reinforcement layer, cerium ions are incorporated into the membrane to protect the ionomer from ROS-mediated degradation. The role of cerium ions as scavengers will be discussed in more detail at the end of the Results section.

These examples demonstrate that predictions for the concentration of ionomer functional groups and the FER with reasonable assumptions are possible for in situ conditions. For the first two examples (shown in Fig. 10 and 11) the assumed values for $\left[\mathrm{H}_{2} \mathrm{O}_{2}\right]$ are higher compared to experimental ${ }^{52,53}$ and 
Table 5 Experimental conditions used in the Fenton test ${ }^{37}$

\begin{tabular}{ll}
\hline Parameter & Values \\
\hline$T$ & $80{ }^{\circ} \mathrm{C}=353.15 \mathrm{~K}$ \\
$A_{\text {membrane }}$ & $c a .25 \mathrm{~cm}^{2}$ \\
$\delta_{\text {membrane }}$ & $50 \mu \mathrm{m}$ \\
{$\left[\mathrm{H}_{2} \mathrm{O}_{2}\right]_{0}$} & $3 \mathrm{wt} \%=0.98 \mathrm{M}$ \\
{$\left[\mathrm{Fe}_{2+}\right]_{0}$} & $13 \mathrm{ppm}$ (impregnated into the membrane) \\
Duration of test & $96 \mathrm{~h}$
\end{tabular}

simulated data. ${ }^{30,31}$ For the last example discussed in the paragraph above, the cerium scavengers incorporated into the membrane lead to a decreased FER; hence the FER value without any cerium additives is estimated to be $10^{-7}$ to $10^{-5} \mathrm{~mol} \mathrm{~cm}{ }^{-2} \mathrm{~h}^{-1}$ ( 2 orders of magnitude higher, see below for discussion). This means that the parameters $\left[\mathrm{H}_{2} \mathrm{O}_{2}\right]$ and $\left[\mathrm{Fe}^{x+}\right]$ have to be set to a higher value to reproduce the fluoride emission rates obtained by Futter et $a .^{36}$

It should, however, be kept in mind that the $0 \mathrm{D}$ reactor can neither account for additional formation mechanisms of radical species (e.g. at Pt surfaces ${ }^{73-75}$ ) and additional membrane degradation mechanisms (such as the ${ }^{\bullet} \mathrm{H}$ mediated membrane degradation $^{13}$ ) nor for potential-dependent redox recycling of iron species. ${ }^{34}$ Furthermore, the experimental $\left[\mathrm{H}_{2} \mathrm{O}_{2}\right]$ values (micromolar range) were obtained under OCV conditions and a temperature of $60{ }^{\circ} \mathrm{C},{ }^{52,53}$ whereas the simulations were performed at $95{ }^{\circ} \mathrm{C}$. The situation is aggravated by the fact that under low humidity conditions the concentrations of $\mathrm{H}_{2} \mathrm{O}_{2}$ and contaminants are higher, as the membrane contains less water. All these effects contribute to the membrane degradation and hence a $\left[\mathrm{H}_{2} \mathrm{O}_{2}\right]$ lower than that used in the simulation might be sufficient to cause the same effects. In this case the $\left[\mathrm{H}_{2} \mathrm{O}_{2}\right]$ used in the simulation can be regarded as an "effective" concentration to trigger the analogue behaviour in the $0 \mathrm{D}$ chemical reactor model. When implementing the input of additional iron species, which are migrating from other parts of the PEMFC into the membrane (as shown in Fig. 9), $\left[\mathrm{H}_{2} \mathrm{O}_{2}\right]$ can be set to a lower value to obtain the same FER values.

\section{Simulation of Fenton experiments}

To demonstrate the versatility of the kinetic framework, ex situ conditions in a Fenton test (i.e. high $\left[\mathrm{H}_{2} \mathrm{O}_{2}\right]$ and (optionally) high $\left[\mathrm{Fe}^{2+}\right]_{0}$ ) were also simulated. In contrast to the fuel cell conditions, in a typical Fenton test a membrane is dipped into a mixture of $\mathrm{H}_{2} \mathrm{O}_{2}$ and $\mathrm{Fe}^{2+}$ salts. Once $\mathrm{H}_{2} \mathrm{O}_{2}$ is consumed completely, the formation of reactive oxygen species, and hence the membrane degradation process, is paused. Sethuraman et $a{ }^{37}{ }^{37}$ measured the fluoride emission for a Nafion ${ }^{\circledR} 112$ ionomer membrane impregnated with $\mathrm{Fe}^{2+}$ ions $(13 \mathrm{ppm})$ and submerged into a $3 \%$ hydrogen peroxide solution. Further experimental details are summarised in Table 5.

For the simulation (Fig. 12) it was assumed that the total iron concentration stays constant within the membrane (no leaching out of $\mathrm{Fe}^{x+}$ ). The only species which are washed out of the membrane are the side chain fragment formed in $\mathrm{R}_{\mathbf{1 4}}$ and HF. The replacement of the $\mathrm{H}_{2} \mathrm{O}_{2}$ solution every 24 hours made it necessary to divide the whole process into $40 \mathrm{D}$ chemical

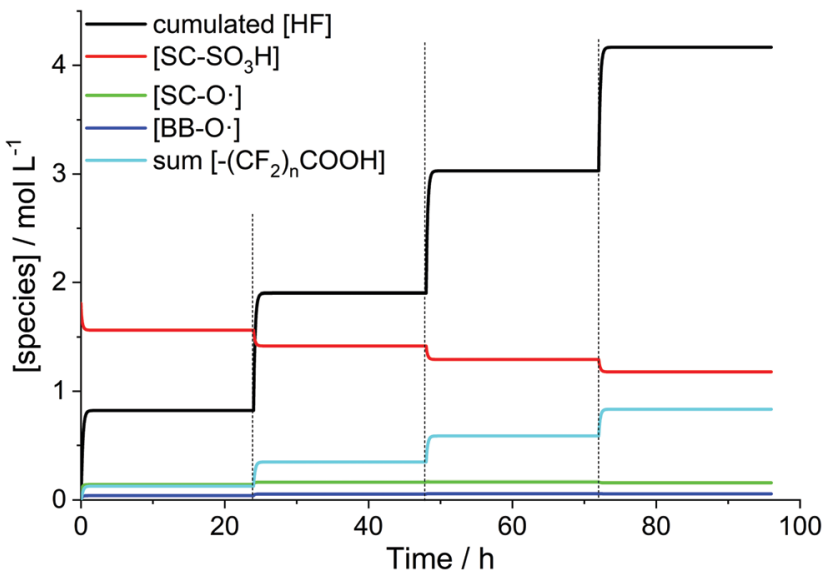

Fig. 12 Simulated time evolution of the concentrations of hydrogen fluoride and ionomer moieties for a Nafion ${ }^{\circledR} 112$ membrane (impregnated with 13 ppm Fe ${ }^{2+}$ ) submerged into a $3 \% \mathrm{H}_{2} \mathrm{O}_{2}$ solution at $80{ }^{\circ} \mathrm{C}^{37}$ The dashed lines mark the replacements of the $\mathrm{H}_{2} \mathrm{O}_{2}$ solution.

reactors. The final concentrations of the chemical species obtained from one chemical reactor serve as initial concentrations for the subsequent chemical reactor. In the case of $\mathrm{HF}$, the concentration values were accumulated. It is clearly visible in Fig. 12 that upon exchange of the $\mathrm{H}_{2} \mathrm{O}_{2}$ solution the degradation reactions resume. They are stopped again when $\mathrm{H}_{2} \mathrm{O}_{2}$ is consumed completely, which is accomplished within 2 hours after the replacement. However, it should be kept in mind that the simulations are geared toward in situ situations, where all species are contained within the hydrophilic domains of the membrane. In contrast, Fenton tests are characterised by a phase boundary between the ionomer membrane and the solution, in which the membrane is immersed. This comparison was done anyway as, under the assumption that there is no leaching of iron species, the Fenton reaction is confined to the ionomer and does not take place outside the membrane. In addition, $\mathrm{H}_{2} \mathrm{O}_{2}$ has to diffuse from the solution into the membrane to initiate the Fenton reaction. For a water swollen Nafion ${ }^{\circledR}$ membrane the time for $\mathrm{H}_{2} \mathrm{O}_{2}$ to diffuse through the whole ionomer membrane $(50 \mu \mathrm{m})$ is calculated to be $9 \mathrm{~s} .{ }^{31}$ This value is considerably lower than the time needed for the total consumption of $\mathrm{H}_{2} \mathrm{O}_{2}$ in the model (ca. $2 \mathrm{~h}$ ); however this might have implications for the concentration within the membrane. In the $0 \mathrm{D}$ model a possible concentration gradient between the membrane and the solution is not considered.

Despite the caveats stated in the paragraph above, an average fluoride emission rate of $2.2 \times 10^{-7} \mathrm{~mol} \mathrm{~cm} \mathrm{~cm}^{-2} \mathrm{~h}^{-1}$ could be obtained from the final hydrogen fluoride concentration $(4.17 \mathrm{M})$. This value is in the same order of magnitude as $4 \times 10^{-7} \mathrm{~mol} \mathrm{~cm}^{-2} \mathrm{~h}^{-1}$ determined by experiment. ${ }^{31,37}$

\section{Membrane lifetime and fluoride emission rate}

The side chain degradation mechanism employed in the kinetic framework leads to gradual loss of the side chain altering the properties of the hydrophilic domain. At first, the mechanical stability is not influenced by the degradation process, as only the head group and the first ether bridge are 
lost. Subsequently, $\mathrm{R}_{16}$ leads to a fragmentation of the main chain at the anchor position followed by shortening of the main chain $\left(\mathrm{R}_{17-23}\right)$. From this point on, the mechanical properties of the membrane are affected.

As stated in the introduction, this paper focuses only on the chemical membrane degradation phenomena, neglecting the mechanically and thermally induced destruction of the ionomer. Hence, their contributions to the lifetime of the membrane cannot be evaluated; however an estimation solely based on the results given by the kinetic framework is possible.

The question which still needs to be answered is how to define a criterion for the membrane lifetime. In principle, the FER as an indicator of the state of health of the membrane could serve as this criterion, although it will be more illustrative if a lifetime given in hours is obtained.

As the time traces of the functional moieties of the ionomer can be easily obtained by the copd routine, the lifetime could be, in principle, defined based on the concentration of a decisive functional group. The most important functional moiety in the ionomer is, without doubt, the sulfonic acid head group being responsible for the conduction of $\mathrm{H}^{+}$. Singh et al. ${ }^{35}$ observed in a COCV AST experiment that a loss of $15.6 \%$ of all sulfonic acid groups did not lead to a diminished proton conductivity. At the same time, the membrane was subjected to thinning (decrease of thickness by $1.4 \%$ ). Lim et al. ${ }^{91}$ suggested that the decrease of $\left[\mathrm{SC}-\mathrm{SO}_{3} \mathrm{H}\right]$ could be compensated by membrane thinning. Moreover, it was also argued that a fraction of the membrane fragments with intact sulfonic acid groups could reside within the membrane sustaining its conductivity. $^{35}$

Based on these considerations, we define the parameter $t_{99}$ as the time span, which is necessary to degrade $99 \%$ of all sulfonic acid groups (i.e. almost completion of reaction $\mathrm{R}_{14}$; due to the kinetics of the degradation reactions a degradation of $100 \%$ is not possible). Since $R_{15}$ and $R_{16}$ feature higher rate constants, all side chains are removed immediately once $\mathrm{R}_{14}$ is completed and only main chain fragments are left.

For different conditions ${ }^{33,35,36}$ the $t_{99}$ values and the associated FER (averaged over $100 \mathrm{~h}$ ) are given in Table 6. It is evident that the higher the $\left[\mathrm{H}_{2} \mathrm{O}_{2}\right]$ and $\left[\mathrm{Fe}^{x+}\right]$ values the shorter the $t_{99}$ value of the membrane. For the FER a reciprocal

Table 6 Calculated tg9 $_{99}$ and FER values (averaged over $100 \mathrm{~h}$ ) for different conditions taken from the simulations above $e^{33,35,36}(T=368.15 \mathrm{~K}$ for all cases)

\begin{tabular}{lll}
\hline Conditions & $t_{99} / \mathrm{h}$ & $\mathrm{FER} / \mathrm{mol} \mathrm{cm}^{-2} \mathrm{~h}^{-1}$ \\
\hline$\left[\mathrm{H}_{2} \mathrm{O}_{2}\right]=4 \mathrm{mM}$ & 360 & $3.70 \times 10^{-7}$ \\
{$\left[\mathrm{Fe}^{2+}\right]_{0}=10 \mathrm{ppm}$} & & \\
{$\left[\mathrm{H}_{2} \mathrm{O}_{2}\right]=5.2 \mathrm{mM}$} & 460 & $5.15 \times 10^{-8}$ \\
{$\left[\mathrm{Fe}^{2+}\right]_{0}=6 \mathrm{ppm}$} & & \\
{$\left[\mathrm{H}_{2} \mathrm{O}_{2}\right]=3 \mathrm{mM}$} & 1920 & $2.86 \times 10^{-8}$ \\
{$\left[\mathrm{Fe}^{x+}\right]=2.5 \mathrm{ppm},\left[\mathrm{Fe}^{2+}\right]_{\mathrm{o}} /\left[\mathrm{Fe}^{3+}\right]_{0}=1$} & & \\
{$\left[\mathrm{H}_{2} \mathrm{O}_{2}\right]=0.5 \mathrm{mM}$} & & \\
{$\left[\mathrm{Fe}^{x+}\right]=2.5 \mathrm{ppm},\left[\mathrm{Fe}^{2+}\right]_{0} /\left[\mathrm{Fe}^{3+}\right]_{0}=1$} & &
\end{tabular}

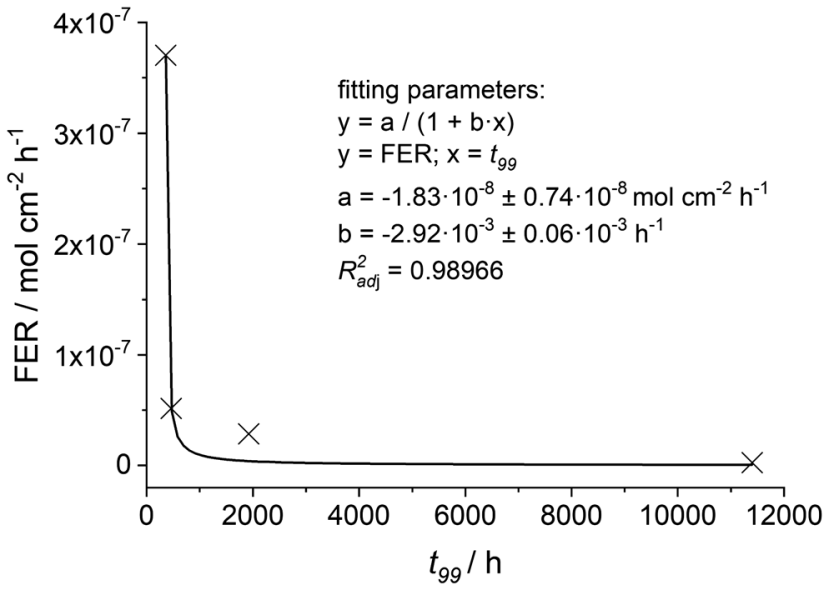

Fig. 13 The calculated fluoride emission rate (averaged over $100 \mathrm{~h}$ ) is plotted as function of $t_{99}$. The crosses mark the four different conditions given in Table 6 and the black line indicates the fitted function.

behaviour compared to $t_{99}$ is visible. Thus, the calculated $t_{99}$ and FER values are plotted and fitted with a reciprocal function (see Fig. 13). With this empirical correlation at hand, it is possible to estimate the $t_{99}$ value based on the fluoride emission rate (averaged over $100 \mathrm{~h}$ ).

Nevertheless, $t_{99}$ should be considered as an upper limit of the membrane lifetime based on chemical degradation phenomena. It is expected to be further decreased by thermal and mechanical degradation. Yoon and Huang ${ }^{93}$ performed gas-phase Fenton experiments, in which a Nafion ${ }^{\circledR} \quad 12$ membrane was conditioned with $\mathrm{Fe}^{x+}$ salts and subjected to gaseous $\mathrm{H}_{2} \mathrm{O}_{2}$ while keeping the membrane under mechanical stress. The authors observed an acceleration of chemical degradation. ${ }^{93}$ In a similar study by Kusoglu et al. ${ }^{94}$ (liquidphase Fenton test of a compressed membrane), it was observed that the fluoride emission increases with the applied pressure. From these findings it was concluded that mechanical and chemical stressors act together, thereby influencing the kinetics of the degradation reactions. ${ }^{94}$

\section{Mitigation of fuel cell degradation with cerium salts}

To protect the chemical integrity of the membrane, two strategies are feasible: First, the input of transition metal contaminants and the amount of $\mathrm{H}_{2} \mathrm{O}_{2}$ produced during operation should be minimized. If this basic mitigation strategy is not possible, the number of reactive oxygen species can be reduced using radical scavengers. In the last two decades, various mitigation strategies have been investigated - an excellent overview is given in the review by Zatoń et $a l^{5}$

Cerium serves either in its ionic form $\left(\mathrm{Ce}^{3+}, \mathrm{Ce}^{4+}\right)^{41-44}$ or as solid cerium oxide (ceria, $\left.\mathrm{CeO}_{2}\right)^{45,46}$ as a radical scavenger. When ceria is incorporated into the membrane, it dissolves under operating conditions and produces both trivalent and tetravalent cerium ions. ${ }^{45,99}$ A detailed scheme describing how $\mathrm{CeO}_{2}$ mitigates membrane degradation by scavenging ROS was presented by Prabhakaran et al. ${ }^{47}$ The most stable oxidation states + III and + IV form a redox couple $\left(E^{0}\left(\mathrm{Ce}^{3+} / \mathrm{Ce}^{4+}\right)=-1.44 \mathrm{~V}\right.$ 
in $0.5 \mathrm{M}$ or $1 \mathrm{M} \mathrm{H}_{2} \mathrm{SO}_{4}{ }^{100}$ ) rendering it a potent reactant in one-electron redox processes (i.e. quenching of radicals). The trivalent ion reacts with ${ }^{\bullet} \mathrm{OH}$ to form $\mathrm{H}_{2} \mathrm{O}$ and $\mathrm{Ce}^{4+}, 83$ whereas the tetravalent ion reacts with $\mathrm{H}_{2} \mathrm{O}_{2}$ to regenerate $\mathrm{Ce}^{3+} \cdot{ }^{95} \mathrm{Ce}^{4+}$ is also known to oxidize $\mathrm{Fe}^{2+}$ to $\mathrm{Fe}^{3+} ;{ }^{98}$ hence the presence of tetravalent cerium ions slows down the Fenton reaction. ${ }^{101}$ Table 7 gives an overview of the kinetic data for the reactions involving $\mathrm{Ce}^{x+}$ species. $^{45,83,95-98,102}$ Wong and Kjeang ${ }^{45}$ estimated the same activation energy for reactions $R_{24}-R_{27}$ in their model to describe the membrane degradation in ceriasupported fuel cells.

To study the influence of cerium scavengers on the ROS-initiated membrane degradation, the reactions from Table 7 were coupled to the main kinetic framework (Table 1). For a set of parameters $\left(\left[\mathrm{H}_{2} \mathrm{O}_{2}\right]=1 \mathrm{mM},\left[\mathrm{Fe}^{2+}\right]_{0}=5 \mathrm{ppm}\right.$ and $\left.T=353.15 \mathrm{~K}\right)$ simulations with different concentrations of $\mathrm{Ce}^{3+}$ were performed (see Fig. 14). Per $\mathrm{Ce}^{3+}$ ion three protons in the membrane are displaced and thus, three sulfonic acid groups (BOL concentration 1.81 M) undergo complexation with $\mathrm{Ce}^{3+} \cdot{ }^{41}$ It is clearly evident that Ce salts mitigate the destructive effects of the ROS. The higher the concentration of the cerium ions, the more ROS are quenched by the $\mathrm{Ce}^{3+} / \mathrm{Ce}^{4+}$ system leading to lower fluoride emission rates and a smaller loss of hydrophilic head groups. When $30 \%$ of the $\mathrm{SC}-\mathrm{SO}_{3} \mathrm{H}$ sites are complexed with $\mathrm{Ce}^{3+}$ (at BOL), the FER (averaged over $100 \mathrm{~h}$ ) is reduced by 2 orders of magnitude.

A situation similar to the dynamic equilibrium between the redox states of iron is evident for the cerium system. Simulations show that more than $99 \%$ of the cerium ions reside in the trivalent state and hence, are active for quenching ${ }^{\bullet} \mathrm{OH}$, the most destructive oxygen species. This is well in line with the modelling results by Gubler et al. ${ }^{101}$ and Wong and Kjeang, ${ }^{45,103}$ who also found that the dominant oxidation state in the cerium system is +III.

Coms et al. ${ }^{41}$ incorporated $\mathrm{Ce}^{3+}$ ions $\left(15 \%\right.$ of $\mathrm{SC}-\mathrm{SO}_{3} \mathrm{H}$ complexed) into the membrane and found that the FER is reduced by 3 orders of magnitude (from $10^{-6} \mathrm{~mol} \mathrm{~cm}{ }^{-2} \mathrm{~h}^{-1}$ to $1.6 \times 10^{-9} \mathrm{~mol} \mathrm{~cm}{ }^{-2} \mathrm{~h}^{-1}$ ). When $\mathrm{Ce}^{3+}$ ions were introduced by spraying on both anode and cathode side (about $1 \%$ of $\mathrm{SC}-\mathrm{SO}_{3} \mathrm{H}$ complexed), the same FER value of $1.6 \times$ $10^{-9}$ mol cm ${ }^{-2} \mathrm{~h}^{-1}$ was measured. ${ }^{41}$ Similar results were presented by Zaton et al., ${ }^{44}$ who observed a reduction of 2 orders of magnitude when loading the membrane with $0.04 \mathrm{mmol} \mathrm{Ce}^{3+} \mathrm{g}^{-1}$ membrane.

The experimental results mentioned here demonstrate that $\mathrm{Ce}^{3+}$ ions are highly effective in protecting the chemical integrity of the membrane. In principle, the simulations illustrate the trend that higher $\left[\mathrm{Ce}^{3+}\right]$ values lead to lower fluoride emission. However, the fact that at a ratio of complexation of $1 \%$ the FER drops by 3 orders of magnitude cannot satisfactorily be explained by the kinetic framework.

A fundamental assumption in the kinetic framework presented here is that all chemical species are distributed homogeneously throughout the membrane, though it is known that cerium ions migrate during the assembly and operation of the fuel cell. Stewart et al. ${ }^{104}$ measured the cerium levels in

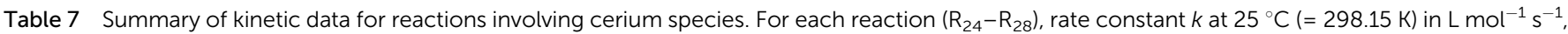
activation energy $E_{\mathrm{a}}$ in $\mathrm{kJ} \mathrm{mol}^{-1}$ and pre-exponential factor $A$ in $\mathrm{L} \mathrm{mol}^{-1} \mathrm{~s}^{-1}$ are given

\begin{tabular}{|c|c|c|c|c|c|}
\hline \multicolumn{3}{|c|}{ Reaction } & \multirow{2}{*}{$\frac{k(T=298.15 \mathrm{~K})\left[\mathrm{L} \mathrm{mol}^{-1} \mathrm{~s}^{-1}\right]}{10^{695}}$} & \multirow{2}{*}{$\frac{E_{\mathrm{a}}\left[\mathrm{kJ} \mathrm{\textrm {mol } ^ { - 1 } ]}\right.}{58^{45 a}}$} & \multirow{2}{*}{$\frac{A\left[\mathrm{~L} \mathrm{~mol}^{-1} \mathrm{~s}^{-1}\right]}{1.45 \times 10^{16}}$} \\
\hline $\mathrm{R}_{24}$ & $\mathrm{Ce}^{4+}+\mathrm{H}_{2} \mathrm{O}_{2} \rightarrow \mathrm{Ce}^{3+}+\cdot \mathrm{OOH}+\mathrm{H}^{+}$ & $r_{24}=k_{24}\left[\mathrm{Ce}^{4+}\right]\left[\mathrm{H}_{2} \mathrm{O}_{2}\right]$ & & & \\
\hline $\mathrm{R}_{25}$ & $\mathrm{Ce}^{4+}+\cdot \mathrm{OOH} \rightarrow \mathrm{Ce}^{3+}+\mathrm{O}_{2}+\mathrm{H}^{+}$ & $r_{25}=k_{25}\left[\mathrm{Ce}^{4+}\right]\left[{ }^{\bullet} \mathrm{OOH}\right]$ & $2.7 \times 10^{695,96}$ & $58^{45 a}$ & $3.92 \times 10^{16}$ \\
\hline $\mathrm{R}_{26}$ & $\mathrm{Ce}^{3+}+\cdot{ }^{\bullet} \mathrm{OH}+\mathrm{H}^{+} \rightarrow \mathrm{Ce}^{4+}+\mathrm{H}_{2} \mathrm{O}$ & $r_{26}=k_{26}\left[\mathrm{Ce}^{3+}\right]\left[{ }^{\bullet} \mathrm{OH}\right]$ & $3 \times 10^{883}$ & $58^{45 a}$ & $4.35 \times 10^{18}$ \\
\hline $\mathrm{R}_{27}$ & $\mathrm{Ce}^{3+}+\cdot{ }^{\bullet} \mathrm{OOH}+\mathrm{H}^{+} \rightarrow \mathrm{Ce}^{4+}+\mathrm{H}_{2} \mathrm{O}_{2}$ & $r_{27}=k_{27}\left[\mathrm{Ce}^{3+}\right][\bullet \mathrm{OOH}]$ & $2.1 \times 10^{597}$ & $58^{45 a}$ & $3.05 \times 10^{15}$ \\
\hline $\mathrm{R}_{28}$ & $\mathrm{Ce}^{4+}+\mathrm{Fe}^{2+} \rightarrow \mathrm{Fe}^{3+}+\mathrm{Ce}^{3+}$ & $r_{28}=k_{28}\left[\mathrm{Ce}^{4+}\right]\left[\mathrm{Fe}^{2+}\right]$ & $1.3 \times 10^{698}$ & 39.7 & $1.20 \times 10^{13}$ \\
\hline
\end{tabular}

${ }^{a}$ For all four reactions the same activation energy is given in ref. 45 .
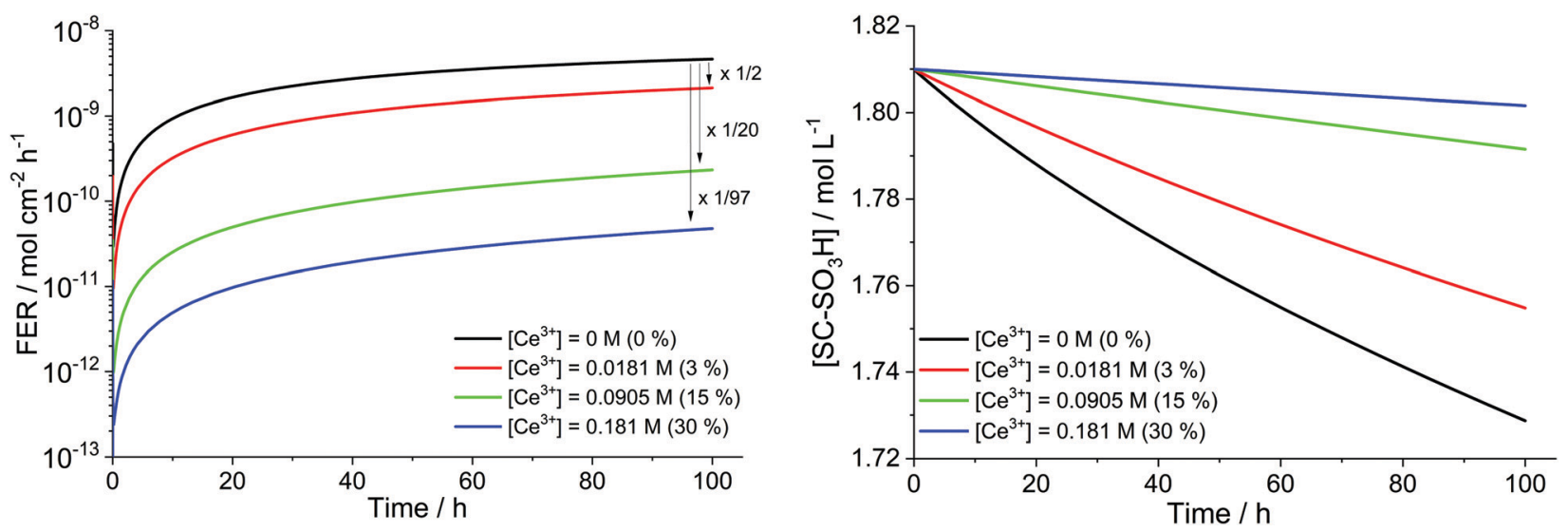

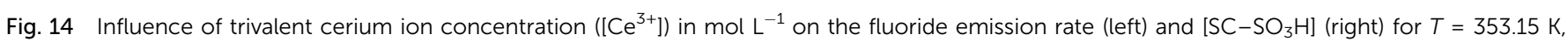

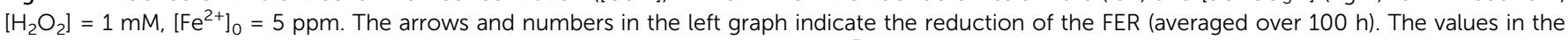
brackets correspond to the percentage of $\mathrm{SC}-\mathrm{SO}_{3} \mathrm{H}$ which are complexed by $\mathrm{Ce}^{3+}$ at $\mathrm{BOL}$. 
Nafion ${ }^{\circledR}$ XL membranes, and found that the cerium level decreased from the BOL value of $7 \mu \mathrm{g} \mathrm{cm}^{-2}$ upon pressing and conditioning and subsequently during accelerated stress testing. The authors concluded that the cerium ions leave the membrane and enrich at both anode and cathode catalyst. ${ }^{104}$ Zaton et $a l .{ }^{44}$ also presented evidence that cerium migrates to the electrodes and is additionally eluted from the fuel cell, which limits the applicability of cerium scavengers in PEMFCs. Moreover, at increased Ce loadings (e.g. of SC- $\mathrm{SO}_{3} \mathrm{H}$ complexed ${ }^{41}$ ) the performance of the fuel cell is also diminished. ${ }^{41,43}$

In addition to the reactions shown in Table 7 other pathways are also possible. A reduction of $\mathrm{Ce}^{4+}$ by $\mathrm{H}_{2}$ or $\mathrm{H}_{2} \mathrm{O}$ could also happen on Pt deposits in the membrane or $\mathrm{Ce}^{3+}$ can be oxidized by hydrogen radicals. ${ }^{42}$ Under operating conditions, $\mathrm{Ce}^{4+}$ is also reduced to $\mathrm{Ce}^{3+}$ electrochemically. ${ }^{45}$ Without doubt, these reactions influence the equilibrium of $\mathrm{Ce}^{3+}$ and $\mathrm{Ce}^{4+}$ and hence, also the radical scavenging.

Instead of using the expensive lanthanide cerium, a cheaper transition metal such as manganese can also be employed to quench ROS due to its rich redox chemistry. ${ }^{41,44}$ A similar kinetic framework for manganese species was presented by Gubler et al. ${ }^{101}$

\section{Conclusions}

The zero-dimensional kinetic framework presented in this work allows to simulate chemical degradation phenomena in a fuel cell and (with caution) also under ex situ (Fenton) conditions. The kinetic framework relies on the assumption that the PFSA ionomer membrane in a fuel cell behaves like a 0D chemical reactor, and hence inhomogeneous distributions of chemical species are not covered here. Nevertheless, the said kinetic framework, which combines published data ${ }^{14-28,33}$ and frameworks, ${ }^{30-36}$ reproduces various sets of recent experimental data ${ }^{33,35-37}$ (concentrations of ionomer moieties and FERs). To account for effects like additional sources of radicals $^{73-75}$ or the potential-dependent redox recycling of iron species, ${ }^{34}$ the used $\mathrm{Fe}^{x+}$ and $\mathrm{H}_{2} \mathrm{O}_{2}$ concentrations might be higher than in a real fuel cell under working or OCV conditions.

At the core of the model is the Fenton reaction between hydrogen peroxide and $\mathrm{Fe}^{2+}$, which leads to the formation of hydroxyl radicals. The role of the Pt catalyst or Pt deposits in the membrane in the overall degradation is not considered in this kinetic framework. This is mainly due to the fact that the dimensionality of the reactor model conflicts with processes happening at phase boundaries such as Pt surfaces, which request a higher dimensionality of the model and the implementation of diffusive processes. The implications of Pt catalyst for the chemical membrane degradation will be addressed in an upcoming publication.

Instead of Pt, the involvement of alternative ORR catalysts in membrane degradation is outlined. Such catalysts offer in principle a cheap, though effective, replacement for precious $\mathrm{Pt}$; however, the demetallation in the case of $\mathrm{Fe}-\mathrm{N}-\mathrm{C}$ should be regarded with care. Leaching of iron species from the catalyst (or other constituents of the fuel cell system) in combination with hydrogen peroxide poses a major threat to the chemical integrity of the membrane. Thus, is it imperative to minimize the Fe contamination and the input of additional Fe species into the system. Not only iron species, but also other metal species like $\mathrm{Ti}^{3+66} \mathrm{Co}^{2+68,69}$ or $\mathrm{Cu}^{+70-72}$ are known to produce ROS. This should be borne in mind when developing and testing new materials and catalysts to be used in PEMFC systems.

Since Fe is present in both the +II and +III oxidation states in our kinetic framework, the interplay of ferrous and ferric ions (redox recycling) was investigated. Interestingly, the simulation results (concentration traces, FERs) do not depend on the oxidation state of $\mathrm{Fe}$ at $t=0$. It was found that a dynamic equilibrium between both oxidation states of iron is established rather rapidly (within several seconds), compared to the long simulation times (usually 100 hours). In this dynamic equilibrium $99 \%$ of the iron resides in the + III state (i.e. the Fenton-inactive redox state), which greatly decelerates the degradation of the membrane. For a real PEMFC system, a potential-dependent redox recycling of Fenton-active iron species was proposed by Wong and Kjeang. ${ }^{34}$ The authors found in their simulations that the fluoride emission is lowered when the system is operated at voltages below $0.7 \mathrm{~V}$, as $\left[\mathrm{Fe}^{2+}\right]$ is decreased.

In an approach to describe membrane lifetimes the parameter $t_{99}$ was introduced. It represents the time necessary to degrade $99 \%$ of all sulfonic acid head groups. A reciprocal correlation between this calculated parameter and the average FER was found. Hence, it is possible to predict chemical membrane lifetimes (or to be more precise, an upper limit) from FER values, which are accessible by experiment. Degradation phenomena of thermal and mechanical nature ${ }^{5-7}$ are not considered here. It can be expected that these degradation mechanisms lower the lifetime based on chemical degradation, as mechanical stress exacerbates the damage induced by chemical stressors. ${ }^{93,94}$

To demonstrate the facile expandability of the kinetic framework, five additional equations describing reactions of $\mathrm{H}_{2} \mathrm{O}_{2}$, ROS and $\mathrm{Fe}^{2+}$ with cerium ions, which act as radical quenchers, are coupled to the main framework. Simulations with the expanded framework show that the addition of cerium ions to the membrane reduces the loss of sulfonic acid head groups and decreases the fluoride emission. Yet, the fact that the FER is reduced by 3 orders of magnitude, when about $1 \%$ of all sulfonic acid groups are complexed with $\mathrm{Ce}^{3+}, 41$ cannot be explained satisfactorily by the extended $0 \mathrm{D}$ reactor model. A reduction of the FER by 2 orders of magnitude is observed when $30 \%$ of all $\mathrm{SC}-\mathrm{SO}_{3} \mathrm{H}$ groups are complexed with $\mathrm{Ce}^{3+}$ (at BOL).

We have developed a routine providing extensive data sets in a short amount of time. Graphical representations generated by the copd routine via gnuplot allow a fast assessment of the data prior to further manipulation of data. A web interface of the kinetic framework is available under http://ptc-pc-139.tugraz.at/ cgi-bin/Membrane_Degradation/. 
In the future, further steps to explore the connection between simulated and experimental data will be undertaken. To do so, the oD chemical reactor model will be integrated into a more extensive fuel cell degradation model.

\section{Conflicts of interest}

There are no conflicts to declare.

\section{Acknowledgements}

Financial support by the Austrian Research Promotion Agency (FFG; project number: 854867 ) is gratefully acknowledged. This work is part of the SoH4PEM (State of Health Monitoring for Proton Exchange Membrane Fuel Cell Stacks) project. The research is partially funded by the Slovenian Research Agency (research core funding no. P2-0401).

\section{Notes and references}

1 I. Staffell, D. Scamman, A. Velazquez Abad, P. Balcombe, P. E. Dodds, P. Ekins, N. Shah and K. R. Ward, Energy Environ. Sci., 2019, 12, 463-491.

2 T. Wilberforce, Z. El-Hassan, F. N. Khatib, A. Al Makky, A. Baroutaji, J. G. Carton and A. G. Olabi, Int. J. Hydrogen Energy, 2017, 42, 25695-25734.

3 R. J. Detz, J. N. H. Reek and B. C. C. van der Zwaan, Energy Environ. Sci., 2018, 11, 1653-1669.

4 M. R. Shaner, H. A. Atwater, N. S. Lewis and E. W. McFarland, Energy Environ. Sci., 2016, 9, 2354-2371.

5 M. Zatoń, J. Rozière and D. J. Jones, Sustainable Energy Fuels, 2017, 1, 409-438.

6 R. Borup, J. Meyers, B. Pivovar, Y. S. Kim, R. Mukundan, N. Garland, D. Myers, M. Wilson, F. Garzon, D. Wood, P. Zelenay, K. More, K. Stroh, T. Zawodzinski, J. Boncella, J. E. McGrath, M. Inaba, K. Miyatake, M. Hori, K. Ota, Z. Ogumi, S. Miyata, A. Nishikata, Z. Siroma, Y. Uchimoto, K. Yasuda, K. Kimijima and N. Iwashita, Chem. Rev., 2007, 107, 3904-3951.

7 A. Kusoglu and A. Z. Weber, Chem. Rev., 2017, 117, 987-1104.

8 A. Collier, H. Wang, X. Z. Yuan, J. Zhang and D. P. Wilkinson, Int. J. Hydrogen Energy, 2006, 31, 1838-1854.

9 D. E. Curtin, R. D. Lousenberg, T. J. Henry, P. C. Tangeman and M. E. Tisack, J. Power Sources, 2004, 131, 41-48.

10 F. D. Coms, ECS Transactions, ECS, 2008, vol. 16, pp. 235-255. 11 L. Ghassemzadeh, K.-D. Kreuer, J. Maier and K. Müller, J. Phys. Chem. C, 2010, 114, 14635-14645.

12 L. Ghassemzadeh and S. Holdcroft, J. Am. Chem. Soc., 2013, 135, 8181-8184.

13 L. Ghassemzadeh, T. J. Peckham, T. Weissbach, X. Luo and S. Holdcroft, J. Am. Chem. Soc., 2013, 135, 15923-15932.

14 F. S. Dainton and J. Rowbottom, Trans. Faraday Soc., 1953, 49, 1160-1173.

15 T. Rigg, W. Taylor and J. Weiss, J. Chem. Phys., 1954, 22, $575-577$.
16 T. Lundström, H. Christensen and K. Sehested, Radiat. Phys. Chem., 2001, 61, 109-113.

17 Y. Lee, C. Lee and J. Yoon, Chemosphere, 2003, 51, 963-971.

18 C. Lee and J. Yoon, Chemosphere, 2004, 56, 923-934.

19 T. Lundström, H. Christensen and K. Sehested, Radiat. Phys. Chem., 2004, 69, 211-216.

20 A. M. Dreizler and E. Roduner, Fuel Cells, 2012, 12, 132-140.

21 P. A. Giguère and I. D. Liu, Can. J. Chem., 1957, 35, 283-293.

22 C. Walling and A. Goosen, J. Am. Chem. Soc., 1973, 95, 2987-2991.

23 G. G. Jayson, B. J. Parsons and A. J. Swallow, J. Chem. Soc., Faraday Trans. 1, 1973, 69, 236-242.

24 B. H. J. Bielski, Photochem. Photobiol., 1978, 28, 645-649.

25 H. Christensen and K. Sehested, Radiat. Phys. Chem., 1981, 18, 723-731.

26 H. Christensen, K. Sehested and H. Corfitzen, J. Phys. Chem., 1982, 86, 1588-1590.

27 H. Christensen and K. Sehested, J. Phys. Chem., 1983, 87, 118-120.

28 P. Maruthamuthu, S. Padmaja and R. E. Huie, Int. J. Chem. Kinet., 1995, 27, 605-612.

29 T. Xie and C. A. Hayden, Polymer, 2007, 48, 5497-5506.

30 A. A. Shah, T. R. Ralph and F. C. Walsh, J. Electrochem. Soc., 2009, 156, B465-B484.

31 L. Gubler, S. M. Dockheer and W. H. Koppenol, J. Electrochem. Soc., 2011, 158, B755-B769.

32 M. Ghelichi, P.-É. A. Melchy and M. H. Eikerling, J. Phys. Chem. B, 2014, 118, 11375-11386.

33 K. H. Wong and E. Kjeang, J. Electrochem. Soc., 2014, 161, F823-F832.

34 K. H. Wong and E. Kjeang, ChemSusChem, 2015, 8, 1072-1082.

35 R. Singh, P. C. Sui, K. H. Wong, E. Kjeang, S. Knights and N. Djilali, J. Electrochem. Soc., 2018, 165, F3328-F3336.

36 G. A. Futter, A. Latz and T. Jahnke, J. Power Sources, 2019, 410-411, 78-90.

37 V. A. Sethuraman, J. W. Weidner, A. T. Haug and L. V. Protsailo, J. Electrochem. Soc., 2008, 155, B119-B124.

38 D. Banham, S. Ye, K. Pei, J. Ozaki, T. Kishimoto and Y. Imashiro, J. Power Sources, 2015, 285, 334-348.

39 C. H. Choi, C. Baldizzone, G. Polymeros, E. Pizzutilo, O. Kasian, A. K. Schuppert, N. Ranjbar Sahraie, M.-T. Sougrati, K. J. J. Mayrhofer and F. Jaouen, ACS Catal., 2016, 6, 3136-3146.

40 R. Chenitz, U. I. Kramm, M. Lefèvre, V. Glibin, G. Zhang, S. Sun and J.-P. Dodelet, Energy Environ. Sci., 2018, 11, 365-382.

41 F. D. Coms, H. Liu and J. E. Owejan, ECS Transactions, ECS, 2008, vol. 16, pp. 1735-1747.

42 M. Danilczuk, S. Schlick and F. D. Coms, Macromolecules, 2009, 42, 8943-8949.

43 A. M. Baker, R. Mukundan, D. Spernjak, E. J. Judge, S. G. Advani, A. K. Prasad and R. L. Borup, J. Electrochem. Soc., 2016, 163, F1023-F1031. 
44 M. Zatoń, B. Prélot, N. Donzel, J. Rozière and D. J. Jones, J. Electrochem. Soc., 2018, 165, F3281-F3289.

45 K. H. Wong and E. Kjeang, J. Electrochem. Soc., 2017, 164, F1179-F1186.

46 B. P. Pearman, N. Mohajeri, R. P. Brooker, M. P. Rodgers, D. K. Slattery, M. D. Hampton, D. A. Cullen and S. Seal, J. Power Sources, 2013, 225, 75-83.

47 V. Prabhakaran, C. G. Arges and V. Ramani, Proc. Natl. Acad. Sci. U. S. A., 2012, 109, 1029-1034.

48 A. Panchenko, H. Dilger, E. Möller, T. Sixt and E. Roduner, J. Power Sources, 2004, 127, 325-330.

49 M. Danilczuk, F. D. Coms and S. Schlick, J. Phys. Chem. B, 2009, 113, 8031-8042.

50 H. S. Wroblowa, Y.-C. Pan and G. Razumney, J. Electroanal. Chem. Interfacial Electrochem., 1976, 69, 195-201.

51 A. M. Gómez-Marín, R. Rizo and J. M. Feliu, Catal. Sci. Technol., 2014, 4, 1685-1698.

52 W. Liu and D. Zuckerbrod, J. Electrochem. Soc., 2005, 152, A1165-A1170.

53 C. Chen and T. Fuller, ECS Transactions, ECS, 2007, vol. 11, pp. 1127-1137.

54 M. Inaba, T. Kinumoto, M. Kiriake, R. Umebayashi, A. Tasaka and Z. Ogumi, Electrochim. Acta, 2006, 51, 5746-5753.

55 H. J. H. Fenton, J. Chem. Soc., Trans., 1894, 65, 899-910.

56 G. Ruppert, R. Bauer and G. Heisler, J. Photochem. Photobiol., A, 1993, 73, 75-78.

57 A. Pozio, R. F. Silva, M. De Francesco and L. Giorgi, Electrochim. Acta, 2003, 48, 1543-1549.

58 W. G. Barb, J. H. Baxendale, P. George and K. R. Hargrave, Trans. Faraday Soc., 1951, 47, 462-500.

59 W. G. Barb, J. H. Baxendale, P. George and K. R. Hargrave, Trans. Faraday Soc., 1951, 47, 591-616.

60 D. D. Papadias, R. K. Ahluwalia, J. K. Thomson, H. M. Meyer, M. P. Brady, H. Wang, J. A. Turner, R. Mukundan and R. Borup, J. Power Sources, 2015, 273, 1237-1249.

61 F. D. Coms, S. Schlick and M. Danilczuk, in The Chemistry of Membranes Used in Fuel Cells: Degradation and Stabilization, ed. S. Schlick, John Wiley \& Sons, Inc., Hoboken, NJ, USA, 2018, pp. 75-106.

62 H. Liu, J. Zhang, F. D. Coms, W. Gu, B. Litteer and H. A. Gasteiger, ECS Transactions, ECS, 2006, vol. 3, pp. 493-505.

63 P. Maletzky, R. Bauer, J. Lahnsteiner and B. Pouresmael, Chemosphere, 1999, 38, 2315-2325.

64 S. M. Andersen, J. Fuel Cell Sci. Technol., 2016, 12, 061010. 65 C. Walling, Acc. Chem. Res., 1975, 8, 125-131.

66 A. Bosnjakovic and S. Schlick, J. Phys. Chem. B, 2004, 108, 4332-4337.

67 L. Ghassemzadeh, K. D. Kreuer, J. Maier and K. Müller, J. Power Sources, 2011, 196, 2490-2497.

68 M. B. Kadiiska, K. R. Maples and R. P. Mason, Arch. Biochem. Biophys., 1989, 275, 98-111.

69 P. M. Hanna, M. B. Kadiiska and R. P. Mason, Chem. Res. Toxicol., 1992, 5, 109-115.

70 J. W. Moffett and R. G. Zika, Environ. Sci. Technol., 1987, 21, 804-810.
71 F. J. Millero, V. K. Sharma and B. Karn, Mar. Chem., 1991, 36, 71-83.

72 A. D. Bokare and W. Choi, J. Hazard. Mater., 2014, 275, 121-135.

73 V. Atrazhev, E. N. Timokhina, S. F. Burlatsky, V. I. Sultanov, T. H. Madden and M. Gummalla, ECS Transactions, ECS, 2008, vol. 6, pp. 69-74.

74 D. Zhao, B. L. Yi, H. M. Zhang and M. Liu, J. Power Sources, 2010, 195, 4606-4612.

75 M. P. Rodgers, B. P. Pearman, L. J. Bonville, D. A. Cullen, N. Mohajeri and D. K. Slattery, J. Electrochem. Soc., 2013, 160, F1123-F1128.

76 M. I. Bro and C. A. Sperati, J. Polym. Sci., 1959, 38, 289-295.

77 K. E. Schwiebert, K. G. Raiford, G. Escobedo and G. Nagarajan, ECS Transactions, ECS, 2006, vol. 1, pp. 303-311.

78 C. Zhou, M. A. Guerra, Z.-M. Qiu, T. A. Zawodzinski and D. A. Schiraldi, Macromolecules, 2007, 40, 8695-8707.

79 N. E. Cipollini, ECS Transactions, ECS, 2007, vol. 11, pp. 1071-1082.

80 M. Danilczuk, A. J. Perkowski and S. Schlick, Macromolecules, 2010, 43, 3352-3358.

81 M. K. Kadirov, A. Bosnjakovic and S. Schlick, J. Phys. Chem. $B, 2005$, 109, 7664-7670.

82 A. Bosnjakovic, M. K. Kadirov and S. Schlick, Res. Chem. Intermed., 2007, 33, 677-687.

83 G. V. Buxton, C. L. Greenstock, W. P. Helman and A. B. Ross, J. Phys. Chem. Ref. Data, 1988, 17, 513-886.

84 T. Tokumasu, I. Ogawa, M. Koyama, T. Ishimoto and A. Miyamoto, J. Electrochem. Soc., 2011, 158, B175-B179.

85 S. Hoops, S. Sahle, R. Gauges, C. Lee, J. Pahle, N. Simus, M. Singhal, L. Xu, P. Mendes and U. Kummer, Bioinformatics, 2006, 22, 3067-3074.

86 T. Madden, D. Weiss, N. Cipollini, D. Condit, M. Gummalla, S. Burlatsky and V. Atrazhev, J. Electrochem. Soc., 2009, 156, B657-B662.

87 Y. Zhao, M. Yamaguchi, E. Tsuchida, Y.-K. Choe and T. Ikeshoji, J. Phys. Chem. C, 2018, 122, 20135-20143.

88 J. D. Rush and B. H. J. Bielski, J. Phys. Chem., 1985, 89, 5062-5066.

89 G. G. Jayson, B. J. Parsons and A. J. Swallow, J. Chem. Soc., Faraday Trans. 1, 1972, 68, 2053-2058.

90 V. A. Sethuraman, J. W. Weidner, A. T. Haug, S. Motupally and L. V. Protsailo, J. Electrochem. Soc., 2008, 155, B50-B57.

91 C. Lim, L. Ghassemzadeh, F. Van Hove, M. Lauritzen, J. Kolodziej, G. G. Wang, S. Holdcroft and E. Kjeang, J. Power Sources, 2014, 257, 102-110.

92 M. Chandesris, R. Vincent, L. Guetaz, J.-S. Roch, D. Thoby and M. Quinaud, Int. J. Hydrogen Energy, 2017, 42, 8139-8149.

93 W. Yoon and X. Huang, ECS Transactions, 2010, vol. 33, pp. 907-911.

94 A. Kusoglu, M. Calabrese and A. Z. Weber, ECS Electrochem. Lett., 2014, 3, F33-F36.

95 G. Czapski, B. H. J. Bielski and N. Sutin, J. Phys. Chem., 1963, 67, 201-203.

96 B. H. J. Bielski, D. E. Cabelli, R. L. Arudi and A. B. Ross, J. Phys. Chem. Ref. Data, 1985, 14, 1041-1100. 
97 D. Meisel, Y. A. Ilan and G. Czapski, J. Phys. Chem., 1974, 101 L. Gubler and W. H. Koppenol, J. Electrochem. Soc., 2011, 78, 2330-2334. 159, B211-B218.

98 G. Dulz and N. Sutin, Inorg. Chem., 1963, 2, 102 T. J. Sworski, H. A. Mahlman and R. W. Matthews, J. Phys. 917-921. Chem., 1971, 75, 250-255.

99 S. A. Hayes, P. Yu, T. J. O’Keefe, M. J. O'Keefe and J. O. 103 K. H. Wong and E. Kjeang, J. Electrochem. Soc., 2019, 166, Stoffer, J. Electrochem. Soc., 2002, 149, C623-C630. F128-F136.

100 E. Wadsworth, F. R. Duke and C. A. Goetz, Anal. Chem., 104 S. M. Stewart, D. Spernjak, R. Borup, A. Datye and 1957, 29, 1824-1825. F. Garzon, ECS Electrochem. Lett., 2014, 3, F19-F22. 